\title{
A Theory of Buyer-Seller Networks
}

\author{
By Rachel E. Kranton and Deborah F. Minehart*
}

\begin{abstract}
This paper introduces a new model of exchange: networks, rather than markets, of buyers and sellers. It begins with the empirically motivated premise that a buyer and seller must have a relationship, a "link," to exchange goods. Networks-buyers, sellers, and the pattern of links connecting them-are common exchange environments. This paper develops a methodology to study network structures and explains why agents may form networks. In a model that captures characteristics of a variety of industries, the paper shows that buyers and sellers, acting strategically in their own self-interests, can form the network structures that maximize overall welfare. (JEL D00, L00)
\end{abstract}

This paper develops a new model of economic exchange: networks, rather than markets, of buyers and sellers. In contrast to the assumption that buyers and sellers are anonymous, this paper begins with the empirically motivated premise that a buyer and seller must have a relationship, or "link," to engage in exchange. Broadly defined, a "link" is anything that makes possible or adds value to a particular bilateral exchange. An extensive literature in sociology, anthropology, as well as economics, records the existence and multifaceted nature of such links. In manufacturing, customized equipment or any specific asset is a link between two firms. ${ }^{1} \mathrm{Re}$ lationships with extended family members, coethnics, or "fictive kin" are links that reduce

Kranton: Department of Economics, University of Maryland, College Park, MD 20742; Minehart: Department of Economics, Boston University, 270 Bay State Road, Boston, MA 02215. We thank Larry Ausubel, Abhijit Banerjee, Eddie Dekel, Matthew Jackson, Albert Ma, Michael Manove, Dilip Mookherjee, two anonymous referees, and numerous seminar participants for invaluable comments. Rachel Kranton thanks the Russell Sage Foundation for its hospitality and financial support. Both authors are grateful for support from the National Science Foundation under Grant Nos. SBR-9806063 (Kranton) and SBR-9806201 (Minehart).

'For example, Brian Uzzi's (1996) study reveals the nature of links in New York City's garment industry. Links embody "fine-grained information" about a manufacturer's particular style. Only with this information can a supplier quickly produce a garment to the manufacturer's specifications. information asymmetries. ${ }^{2}$ Personal connections between managers and bonds of trust are links that facilitate business transactions. ${ }^{3}$ There is now a large body of research on how such bilateral relationships facilitate cooperation, investment, and exchange. Some research also considers how an alternative partner or "outside option" affects the relationship. ${ }^{4}$ However, there has been virtually no attempt to examine the realistic situation in which both buyers and sellers may have costly links with multiple trading partners.

This paper develops a theory of investment and exchange in a network, where a network is a group of buyers, sellers, and the pattern of the links that connect them. An economic theory of networks must consider questions not encountered when buyers and sellers are assumed to be anonymous. Because a buyer can obtain a good

\footnotetext{
${ }^{2}$ See, for example, Avner Greif (1993), Janet Tai Landa (1994), and Kranton (1996). These links are particularly important in developing countries, e.g., Hernando de Soto (1989). They also facilitate international trade (Alessandra Casella and James E. Rauch, 1997).

${ }^{3}$ For a classic description see Stewart Macauley (1963). John McMillan and Christopher Woodruff (1999) show the importance of ongoing relations between firms in Vietnam for the extension of trade credit.

${ }^{4}$ The second-sourcing literature considers how an alternate source alters the terms of trade between a buyer and supplier. See, for example, Joel S. Demski et al. (1987), Joseph Farrell and Nancy T. Gallini (1988), David T. Scheffman and Spiller (1992), and Michael H. Riordan (1996). Susan Helper and David I. Levine (1992) study an environment where the "outside option" is a market.
} 
from a seller only if the two are linked, the pattern of links affects competition for goods and the potential gains from trade. Many new questions arise: Given a pattern of links, how might exchange take place? Who trades with whom and at what "equilibrium" prices? Is the outcome of any competition for goods efficient? The link pattern itself is an object of study. What are the characteristics of efficient link patterns? What incentives do buyers and sellers have to build links, and when are these individual incentives aligned with social welfare?

Networks are interesting, and complex, exchange environments when buyers have links to multiple sellers and sellers have links to multiple buyers. We see multiple links in many settings. The Japanese electronics industry is famous for its interconnected network structure (see e.g., Toshihiro Nishiguchi, 1994). Manufacturers work with several subcontractors, transferring know-how and equipment, and "qualify" these subcontracters to assemble specific final products and ship them to customers. Subcontractors, in turn, shift production to fill the orders of different manufacturers. Similarly, in Modena, Italy, the majority of artisans who assemble clothing for garment manufacturers work for at least three clients. These manufacturers in turn spread their work among many artisans (Mark Lazerson, 1993). ${ }^{5}$ Annalee Saxenian (1994) attributes the innovative successes of Silicon Valley to its interconnected, rather than vertically integrated, industrial structure, and Allen J. Scott (1993) reaches a similar conclusion in his study of electronics and engineering subcontracting in the Southern Californian defense industry.

In this paper, we explore two reasons why networks emerge, one economic, the other strategic. First, networks can allow buyers and sellers collectively to pool uncertainty in demand, a motive we see in many of the above examples. When sellers have links to more buyers, they are insulated from the difficulties facing any one buyer. And when buyers purchase from the same set of sellers, there is a saving in overall investment costs. As for the strategic motivation, multiple links can enhance an agent's com-

\footnotetext{
${ }^{5}$ Elsewhere in the garment industry, we find a similar pattern (Uzzi, 1996; Pamela M. Cawthorne, 1995).
}

petitive position. With access to more sources of supply (demand), a buyer (seller) secures better terms of trade.

To capture these motivations we specify a game where buyers form links, then compete to obtain goods from their linked sellers. We implicitly assume that agents do not act cooperatively; they cannot write state-contingent, long-term binding contracts to set links, future prices, or side payments. ${ }^{6}$ We consider a stylized general setting: Sellers can each produce one (indivisible) unit of output. Buyers desire one unit each and have private, uncertain valuations for a good. ${ }^{7} \mathrm{~A}$ buyer can purchase from a seller if and only if the two are linked. We then ask: What is the relationship between agents' individual self-interests and collective interests? Can buyers and sellers, acting noncooperatively to maximize their own profits, form a network structure that maximizes overall economic surplus?

To answer these questions, we first explore the relationship between the link pattern and agents' competitive positions in a network. We represent competition for goods by a generalization of an ascending-bid auction, analogous to the fictional Walrasian auctioneer in a market setting. ${ }^{8}$ Our first set of results shows that this natural price-formation process can lead to an efficient allocation of goods in a network. The buyers that value the goods the most obtain the goods, subject only to the physical constraints

\footnotetext{
${ }^{6}$ Such contracts may be difficult to specify and enforce and are even likely to be illegal. An established literature in industrial organization considers how contractual incompleteness shapes economic outcomes (Oliver E. Williamson, 1975; Sanford J. Grossman and Oliver D. Hart, 1986; Hart and John Moore, 1990).

${ }^{7}$ This setting captures the characteristics of at least the following industries particularly well: clothing, electronic components, and engineering services. They share the following features: uncertain demand for inputs because of frequently changing styles and technology, supply-side investment in quality-enhancing assets, specific investments in buyer-seller relationships, and small batches of output made to buyers' specifications. In short, sellers in these industries could be described as "flexible specialists," to use Michael J. Piore and Charles F. Sabel's (1984) term. See above references for studies of apparel industries. Edward H. Lorenz (1989), Scott (1993), and Nishiguchi (1994) study the engineering and electronics industries in southern California, Japan and Britain, and France, respectively.

${ }^{8}$ This auction model can be used whenever there are multiple, interlinked buyers and sellers and has several desirable properties including ease of calculating payoffs.
} 
of the link pattern. Furthermore, the prices reflect the link pattern. A buyer's revenues are exactly the marginal social value of its participation in the network. ${ }^{9}$

Our main result shows that when buyers compete in this way, their individual incentives to build links can be aligned with economic welfare. Efficient network structures are always an equilibrium outcome. Indeed, for small link costs, efficient networks are the only equilibria. These results may seem surprising in a setting where buyers build links strategically, and especially surprising in light of our finding that buyers may have very asymmetric positions in efficient networks. Yet, it is the ex post competition for goods that yields efficient outcomes. Because of competition, no buyer can capture surplus generated by the links of other buyers. Rather, a buyer's profit is equal to its contribution to overall economic welfare.

By studying competitive buyers and sellers, this paper advances the economic theory of networks. ${ }^{10}$ The most closely related work is by Matthew O. Jackson and Asher Wolinsky (1996) who examine strategic link formation in a general setting. ${ }^{11}$ They find, using a value function that allocates network surplus to the nodes (players), that efficient networks need not be stable. In our economic environment agents face uncertainty, asymmetric information, and contractual incompleteness. These features constrain the possible allocations of surplus and

\footnotetext{
${ }^{9}$ These revenues are robust to different models of competition. By the payoff equivalence theorem (Roger B. Myerson, 1981), any mechanism that allocates goods efficiently must yield the same marginal revenues. We discuss this point further below.

${ }^{10}$ By theory of "networks," we mean theory that explicitly examines links between individual agents. The word "networks" has been used in the literature to describe many phenomena. "Network externalities" describes an environment where an agent's gain from adopting a technology depends on how many other agents also adopt the technology (see Michael L. Katz and Carl Shapiro, 1994). In this and many other settings, the links between individual agents may be critical to economic outcomes, but have not yet been incorporated in economic modeling.

${ }^{11}$ Much previous research on networks (e.g., Myerson, 1977; Bhaskar Dutta et al., 1998) employs cooperative equilibrium concepts. There is also now a growing body of research on strategic link formation (see e.g., Jackson and Alison Watts, 1998; Venkatesh Bala and Sanjeev Goyal, 2000). Ken Hendricks et al. (1999) study strategic formation of airline networks.
}

make efficiency more difficult to achieve. Furthermore, we focus on a specific environment, that of buyers and sellers. The combinatoric methods we develop may be used to examine other bipartite settings, such as supervisory hierarchies in firms and international trading blocs. $^{12}$

More generally, this research adds to our understanding of economic institutions. Following R. H. Coase (1937), economists have distinguished between market and nonmarket institutions. Networks are nonmarket institutions with important market-like characteristics: exchange is limited to linked pairs, but buyers and sellers may form links strategically and compete. The theory here captures both aspects of networks. We can use this theory to compare networks to other institutions on either side of the spectrum-markets and vertically integrated firms. ${ }^{13}$ Furthermore, there are many institutional features of networks that can be built onto the basic structure developed here. We indicate directions for future research in the conclusion.

The rest of the paper is organized as follows. Section I constructs the basic model of networks and develops notions of efficiency and competition for the network setting. Sections II and III consider individual incentives to build links and the efficiency of link patterns. Section IV concludes.

\section{Competition and Exchange in Buyer-Seller Networks}

This section develops a theory of competition and exchange in networks. We begin with a basic model of buyers, sellers, and links. We then develop a model of competition in a network.

\section{A. The Basic Model of Buyer-Seller Networks}

There are $\bar{B}$ buyers, each of whom demands one indivisible unit of a good. We denote the set of buyers as B. Each buyer $i$, or $b_{i}$, has a random valuation $v_{i}$ for a good. The valuations

\footnotetext{
${ }^{12}$ In our analysis we use a powerful, yet intuitive, result from the mathematics of combinatorics known as the Marriage Theorem. With this Theorem we can systematically analyze bipartite network structures.

${ }^{13}$ See Kranton and Minehart (2000b).
} 
are independently and identically distributed on $[0, \infty)$ with continuous distribution $F$. We assume the distribution is common knowledge, and the realization of $v_{i}$ is private information. There are $\bar{S}$ sellers who each have the capacity to produce one indivisible unit of a good at zero cost. We denote the set of sellers by $\mathbf{S}$.

A buyer can obtain a good from a seller if and only if the two are linked. E.g., a link is a specific asset, and with this asset the buyer has a value $v_{i}>0$ for the seller's good. We use the notation $g_{i j}=1$ to indicate that a buyer $i$ and a seller $j$ are linked and $g_{i j}=0$ when they are not. These links form a link pattern, or graph, G. ${ }^{14}$ A network consists of the set of buyers and sellers and the link pattern.

In a network, the link pattern determines which buyers can obtain goods from which sellers; that is, the link pattern determines the feasible allocations of goods. An allocation, $\mathbf{A}$, is feasible only if it respects the pattern of links. That is, a buyer $i$ that is allocated seller $j$ 's good must actually be linked to seller $j .{ }^{15}$ In addition, no buyer can be allocated to more than one seller's good, and no seller's good can be allocated to more than one buyer. ${ }^{16}$

To tell us when an allocation of goods is feasible in a given network, we use the Marriage Theorem-a result from the mathematics of combinatorics and an important tool for our analysis. ${ }^{17}$ The theorem asks: Given populations of women and men, when it is possible to pair each woman with a man who she knows, and no man or woman is paired more than once? In our setting, the buyers are "women," the sellers are "men," and the links indicate which women know which men. To use this theorem, it is convenient to define the set of sellers linked to a particular set of buyers, and vice versa. For a

\footnotetext{
${ }^{14}$ It is often convenient to write $\mathbf{G}$ as a $\bar{B} \times \bar{S}$ matrix where the element $g_{i j}$ indicates whether buyer $i$ and seller $j$ are linked.

${ }^{15}$ An allocation of goods, $\mathbf{A}$, can be written as a $\bar{B} \times \bar{S}$ matrix, where $a_{i j}=1$ when $b_{i}$ is allocated a good from $s_{j}$ and $a_{i j}=0$ otherwise.

${ }^{16}$ Formally, an allocation $\mathbf{A}$ is feasible given graph $\mathbf{G}$ if and only if $a_{i j} \leq g_{i j}$ for all $i, j$ and for each buyer $i$, if there is a seller $j$ such that $a_{i j}=1$ then $a_{i k}=0$ for all $k \neq j$ and $a_{l j}=0$ for all $l \neq i$.

${ }^{17}$ Also known as Hall's Theorem, see R. C. Bose and B. Manvel (1984 pp. 205-09) or other combinatorics/graph theory text for an exposition.
}

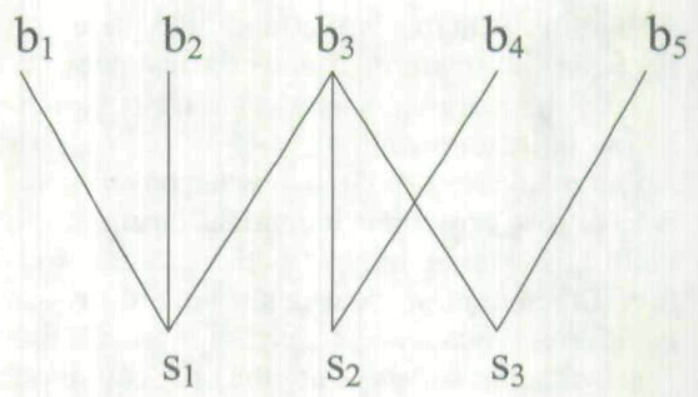

Figure 1. EXAMPLe OF A BUYER-SELLER Network

subset of buyers $\mathcal{B}$, let $L(\mathcal{B})$ denote the set of sellers linked to any buyer in $\mathcal{B}$. We call $L(\mathcal{B})$, $\mathcal{B}$ 's linked set of sellers and say the buyers in $\mathcal{B}$ are linked, collectively, to these sellers. Similarly, for a subset of sellers $S$, let $L(S)$ denote these sellers' linked set of buyers.

THE MARRIAGE THEOREM: For a subset of sellers $S$ containing $S$ sellers and for a subset of buyers $\mathcal{B}$ containing $B$ buyers, there is a feasible allocation of goods such that every buyer in $\mathcal{B}$ obtains a good from a seller in $S$ if and only if every subset $\mathcal{B}^{\prime} \subseteq \mathcal{B}$ containing $k$ buyers is linked, collectively, to at least $k$ sellers in $S$, for each $k, 1 \leq k \leq B .{ }^{18}$

To determine whether an allocation of goods is feasible in a given network, we simply use the counting algorithm provided by the Marriage Theorem. Our first example demonstrates.

Example 1 [Feasible Allocations of Goods in a Network]: In Figure 1 ask whether there is a feasible allocation in which buyers $b_{1}, b_{2}$, and $b_{3}$ all obtain goods. Eyeing the graph, it is clear the answer is no. The Marriage Theorem gives us the following method to prove such an outcome in general: Take the set of buyers $\left\{b_{1}, b_{2}\right.$, $\left.b_{3}\right\}$. Consider all subsets with $k=1,2,3$ buyers. Then count the number of sellers in their linked sets. In this network, there are three sellers in the linked set of $\left\{b_{1}, b_{2}, b_{3},\right\}$, that is $L\left(\left\{b_{1}, b_{2}, b_{3}\right\}\right)=\left\{s_{1}, s_{2}, s_{3}\right\}$. The subset $\left\{b_{1}, b_{2}\right\}$, however, has only one seller in its

\footnotetext{
${ }^{18}$ Note that not all sellers need to be paired to a buyer, and a necessary condition for the proposition to hold is that $S \geq B$.
} 
linked set: $L\left(\left\{b_{1}, b_{2}\right\}\right)=\left\{s_{1}\right\}$. It must contain at least two sellers to satisfy the theorem. Therefore, there is no feasible allocation in which buyers 1,2 , and 3 all obtain goods. In contrast, there is a feasible allocation in which buyers $b_{2}, b_{3}$, and $b_{4}$ all obtain goods ( $b_{2}$ from $s_{1}, b_{3}$ from $s_{3}$, and $b_{4}$ from $s_{2}$ ). The condition of the theorem is satisfied; there are three sellers in the linked set of $\left\{b_{2}, b_{3}\right.$, $\left.b_{4}\right\}$. There are two sellers in the linked set of each subset of two buyers, and each single buyer is linked to at least one seller.

\section{B. Gains from Exchange and Efficient Allocations of Goods}

Economic surplus is generated when buyers procure goods from sellers. The level of surplus will depend on which buyers obtain goods, since buyers' valuations differ. Let $\mathbf{v}=\left(v_{1}, \ldots\right.$, $v_{\bar{B}}$ ) be a vector of buyers' realized valuations. The economic surplus associated with an allocation $\mathbf{A}$ is the sum of the valuations of the buyers that secure goods in $\mathbf{A}$. We denote the surplus as $w(\mathbf{v}, \mathbf{A}){ }^{19}$

We focus on the allocations that yield the highest possible surplus, given the network link pattern. As we saw above, the link pattern constrains the allocation of goods. It may not be feasible for a buyer to obtain a good even though it has a high valuation. Of the feasible allocations, an efficient allocation yields the highest surplus from exchange. In this allocation, the buyers with the highest valuations of goods obtain goods whenever possible given the link pattern. ${ }^{20}$ We denote the efficient allocation by $\mathbf{A}^{*}(\mathbf{v} ; \mathbf{G})$.

The next example demonstrates the efficient allocation of goods in a network for a particular realization of buyers' valuations. In this allocation, a buyer that has a high valuation does not obtain a good. Yet, the allocation yields the highest possible surplus, given the pattern of links.

\footnotetext{
${ }^{19}$ We can write $w(\mathbf{v}, \mathbf{A})=\mathbf{v} \cdot \mathbf{A} \cdot \mathbf{1}$, where $\mathbf{1}$ is an $\bar{S} \times$ 1 matrix where each element is 1 .

${ }^{20}$ Several allocations may yield the same surplus. However, without loss of generality, we can restrict attention to equivalent allocations - allocations in which the same subsets of buyers obtain goods and the same subset of sellers produce goods. This is because buyer $i$ earns $v_{i}$ in any allocation in which it obtains a good and seller $j$ 's cost does not depend on which buyer obtains its good.
}

Example 2 [Efficient Allocation of Goods in a Network]: Consider again the network in Figure 1. Suppose buyers' realized valuations have the following order: $v_{1}>v_{2}>v_{3}>v_{4}>v_{5}$. For these valuations, the efficient allocation pairs $b_{1}$ with $s_{1}, b_{3}$ with $s_{3}$, and $b_{4}$ with $s_{2}$. The surplus from this allocation is $v_{1}+v_{3}+v_{4}$. The only other allocations that could yield higher surplus would allocate goods to buyers $\left\{b_{1}, b_{2}\right.$, $\left.b_{3}\right\}$ or $\left\{b_{1}, b_{2}, b_{4}\right\}$. But, using the Marriage Theorem, we see that these allocations are not feasible given this link pattern.

By taking the efficient allocation of goods for each realization of buyers' valuations, we can determine the highest possible expected surplus from exchange in a given network. Let $H(\mathbf{G})$ be the maximal gross economic surplus obtainable for a link pattern $\mathbf{G} .{ }^{21}$ We have

$$
H(\mathbf{G}) \equiv E_{\mathbf{v}}\left[w\left(\mathbf{v}, \mathbf{A}^{*}(\mathbf{v} ; \mathbf{G})\right)\right]
$$

where the expectation is taken over all the possible realizations of buyers' valuations. ${ }^{22}$

\section{Competition in a Network}

With the basic model in hand, we now develop a model of competition in a network. We use this model to examine how link patterns affect prices and allocations of goods. The generalization of an English, or ascending-bid, auction that we construct allows for an easy, reasonable, yet exact analysis where we can "see" the competition. ${ }^{23}$ For any realization of buyers' valuations, we can compute the equilibrium allocation, prices, and division of surplus.

We view the auction as an abstraction of the

${ }^{21}$ Later, when we introduce link and investment costs, we will distinguish this value from net economic surplus.

${ }^{22}$ This expectation is straightforward to calculate. The efficient allocation depends only on the ordering of buyers' valuations, not their absolute levels. The expectation, $H(\mathbf{G})$, can be written as an expectation over the order statistics of the distribution $F$ (see Kranton and Minehart, 2000b).

${ }^{23}$ Gabrielle Demange et al. (1986) develop an ascending-bid auction for multiple buyers and sellers and general preferences. They do not analyze, however, strategic bidding. We solve for a perfect Bayesian equilibrium of the auction game. Independently, Faruk Gul and Ennio Stacchetti (2000) also show that truthful bidding is an equilibrium outcome of such an ascending-bid auction. 
way goods are actually allocated and prices negotiated in a network setting, in a sense similar to the fiction of the Walrasian auctioneer. ${ }^{24}$ As in a market, the outcome of the competition has several desirable features. First, the allocation of goods is efficient. Despite that buyers' valuations are private information, the buyers with the highest valuations obtain goods whenever possible given the link pattern. Second, the resulting payoffs are "stable;" no buyer and seller can renegotiate the prices or allocation to their mutual benefit. ${ }^{25}$ The prices themselves reflect the social opportunity costs of exchange. We will see below that these properties are critical for buyers to have the correct incentives to build links.

We provide an overview of the auction here and refer the reader to Appendix A for a formal analysis.

Recall, first, a standard ascending-bid auction with one seller. The price rises from zero, and each buyer decides at each moment whether to remain in the bidding or drop out. As is well known, it is a weakly dominant strategy for each buyer to remain in the bidding until the price reaches its valuation. The price then rises until it reaches the second-highest valuation, and the buyer with the highest valuation secures the good at this price. As long as the number of buyers in the bidding exceeds the supply (of one), the price rises. As soon as the number of bidders equals the supply, the auction "clears."

In our generalization, sellers simultaneously hold ascending-bid auctions, where the going price is the same across all sellers. As this price rises from zero, each buyer decides whether to drop out of the bidding of each of its linked sellers' auctions. The price rises until enough buyers have dropped out so that there is a subset of sellers for whom "demand equals supply." We call such a subset a clearable set of sellers. The auctions of these sellers "clear" at the cur-

\footnotetext{
${ }^{24}$ There are, however, some instances where auctions are actually used, as in defense subcontracting and the shoe industry in Brazil (Hubert Schmitz, 1995 p. 14).

${ }^{25}$ Because only buyer-seller pairs generate surplus, the outcome is also in the core (Lloyd S. Shapley and Martin Shubik, 1972). Kranton and Minehart (2000a) considers general properties of pairwise-stable payoffs in networks. The auction yields the lowest payoffs for sellers in the set of all pairwise-stable payoffs.
}

rent price. (Appendix A shows the clearing rule is well defined.) If there are remaining sellers, the price continues to rise until all sellers have sold their goods. We prove that it is an equilibrium (following elimination of weakly dominated strategies) for each buyer to remain in the bidding in each of its linked sellers' auctions up to its valuation of a good.

The next example illustrates the auction and demonstrates how a link pattern shapes the competition for goods.

\section{Example 3 [Auction Representation of Com-} petition in a Network]: In Figure 1, we suppose that buyers' valuations are realized in the order $v_{1}>v_{2}>v_{3}>v_{4}>v_{5}>0$. At $p=0$, the demand exceeds supply for all subsets of sellers. The price rises until it reaches $v_{5}$ when $b_{5}$ drops out of the auction of $s_{3}$. Now $\left\{s_{2}, s_{3}\right\}$ constitutes a clearable set of sellers; i.e., there are only two buyers $\left(b_{3}\right.$ and $\left.b_{4}\right)$ remaining in the bidding for these sellers' goods and there is a feasible allocation in which these buyers obtain goods from these sellers. The buyers each pay a price of $p=v_{5}$. Buyer 3 purchases from $s_{3}$, while buyer 4 purchases from $s_{2}$. There are still two buyers, $b_{1}$ and $b_{2}$, who demand the remaining good of $s_{1}$. Since there is excess demand for $s_{1}$, the price continues to rise. The price rises until it reaches $v_{2}$ at which point $b_{2}$ drops out. Buyer 1 purchases from $s_{1}$ at $p=v_{2}$. Note that the auction achieves the efficient allocation of goods. As we discussed in the previous example, the efficient allocation given the link pattern is for $b_{1}, b_{3}$, and $b_{4}$ to purchase goods.

For any network, we can easily calculate the payoffs from this equilibrium of the auction; indeed, the ease of calculation is a useful feature of this model of competition. Given a link pattern $\mathbf{G}$, let $V_{i}^{b}(\mathbf{G})$ denote the expected payoff to buyer $i$ in this equilibrium, and let $V_{j}^{s}(\mathbf{G})$ denote the expected payoff to seller $j$. We will refer to these payoffs as " $V$-payoffs." We can calculate agents' $V$-payoffs using the order statistics of the distribution $F .^{26}$ Let $X^{n: B}$ be the random

\footnotetext{
${ }^{26}$ See Kranton and Minehart (2000b) for the proof that we can restrict attention to the ordering of buyers' valuations.
} 


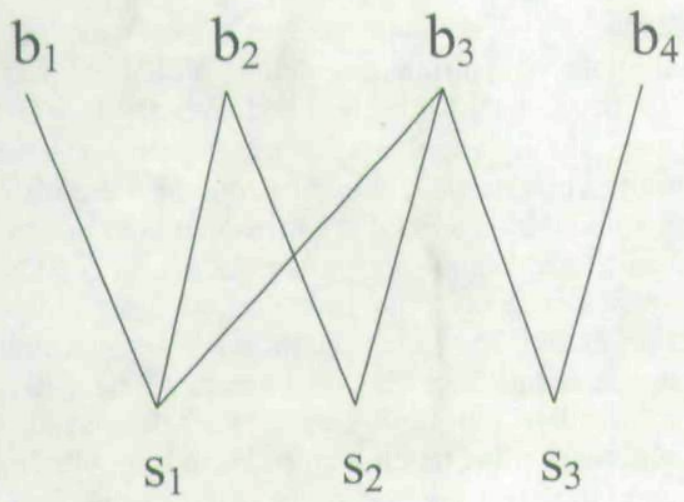

FIGURE 2. NETWORK FOR EXAMPLE 4

variable which is the $n$th highest valuation of $B$ buyers, that is $X^{n: B}$ is the $n$th order statistic. The following example demonstrates the calculation of expected payoffs.

\section{Example 4 [Expected Payoffs from Competi-} tion in a Network]: In Figure 2, for any realization of buyers' valuations, the price will rise until it reaches the lowest valuation of the buyers, $X^{4: 4}$. The three buyers with the top three valuations will then purchase at that price. A buyer expects to have the highest, second highest, third highest, or lowest valuation with equal probability. The $V$-payoffs for each buyer are therefore $1 / 4 E X^{1: 4}+1 / 4 E X^{2: 4}+1 / 4 E X^{3: 4}-$ $3 / 4 E X^{4: 4}$.

This representation of competition in a network has several properties that any frictionless model of network competition should satisfy. First, the equilibrium allocation of goods is efficient. The buyers that value goods the most obtain goods, subject to the constraints of the link pattern. ${ }^{27}$ Example 3 demonstrates this feature. Despite that buyers have private information, buyers bid truthfully. They do not hedge their bids or adopt other strategies that would lead to inefficient allocation of goods. Second, the allocation and prices together are pairwise stable. That is, the surplus that any linked buyer and seller could generate by exchanging a good does not exceed their joint payoffs. Intuitively,

${ }^{27}$ Since all efficient allocations are unique up to equivalence, the auction selects a unique allocation. no linked buyer and seller, or indeed any coalition of agents, can renegotiate and strike a better deal.

PROPOSITION 1: Given the link pattern, for each realization of buyers' valuations, the equilibrium allocation of goods is efficient and the allocation and prices are pairwise stable.

The intuition behind these two properties is that, in this equilibrium, a buyer pays a price exactly equal to the social opportunity cost of obtaining a good. The price a buyer pays does not depend on its own valuation, so there is no incentive not to bid truthfully. In equilibrium, a buyer $i$ pays the seller the valuation of the "next-best" buyer, that is, the highestvaluation buyer that would have obtained a good in $i$ 's place. This price is just high enough so that no competing buyer will want to offer a seller a higher price. For example, in the equilibrium described above for Figure 1, buyer $b_{3}$ pays the valuation of $b_{5}{ }^{28}$

A third feature of this model of competition is that the payoffs in this equilibrium satisfy desirable comparative statics properties of "supply and demand" in a link pattern. For a buyer, increasing its access to supply by adding a link to another seller weakly decreases the price it expects to pays, and vice versa for a seller. The payoffs of other agents also change in natural ways, e.g., the payoffs of other buyers linked to the seller with the additional link weakly decrease. $^{29}$

In our treatment of networks thus far, we have taken the links that connect buyers and sellers as given. This section demonstrates a model of competition that uniquely associates "stable" prices and an efficient allocation with every link pattern.

\footnotetext{
${ }^{28}$ These equilibrium properties are well-known features of Vickrey-Clark-Grove mechanisms. For discussion in pairwise settings, see Herman B. Leonard (1983) and Alvin E. Roth and Marilda A. Oliveira Sotomayor (1990). Another way to describe this result is that buyers pay the lowest "Walrasian" price for a clearable set of sellers. That is, for any clearable set of sellers, there is a continuum of prices such that demand equals supply. The equilibrium of the auction picks out the lowest price.

${ }^{29}$ Kranton and Minehart (2000a) provides a general analysis of how changes in the link pattern affect different agents' payoffs.
} 
In the next part of the paper, we turn to the formation of the network. We will see that the incentives to form links depend on the properties of the competitive process.

\section{Strategic Link Formation and Efficient Link Patterns}

In this section we examine buyers' strategic incentives to form links. We consider, in particular, the relationship between buyers' individual incentives and overall economic welfare. We examine the simplest setting: buyers choose links to an exogenously given set of productive sellers. ${ }^{30}$ In a two-stage game, buyers first simultaneously choose links. Second, buyers learn their valuations and compete in the auction specified above. As mentioned earlier, implicit in this structure is that the buyers cannot use long-term complete contingent contracts to assign individual links, future prices, or allocations. We think of investments in links as long-run investments in anticipation of short-run uncertain demand for goods.

In this analysis, we assume that there are welfare gains when buyers share the productive capacity of sellers. We call these welfare gains economies of sharing and assume that there are fewer sellers than buyers, $\bar{S}<\bar{B}$. The gain from fewer sellers arises from the variability of buyers' valuations and the implicit assumption that productive capacity is costly. (In the next section, we explicitly introduce these costs.) To see why, consider the case of three buyers. If sellers' capacity is costly, it may be optimal for the buyers to share the capacity of just two sellers. The capacity could be allocated to the two buyers that ultimately have the highest valuations for goods. While only two buyers obtain goods, there is a savings in the cost of one unit of

\footnotetext{
${ }^{30}$ In Section III, we endogenize the number of productive sellers. Other questions, such as sellers' incentives to build links to buyers are also of interest. The current analysis can be used to give insight to such network formation games. For instance, if the sellers had uncertain costs and invested in links and if the buyers had fixed common valuations, then our subsequent analysis could be carried out identically just with buyers' and sellers' places exchanged. We could also easily examine a setting where buyers and sellers invest in individual links.
}

capacity. $^{31}$ The same economies of scale underly the "repairman problem" (William Feller, 1950; Michael Rothschild and Gregory J. Werden, 1979) where agents use repair services only when needed. Similar economies are also exploited by intermediary firms that hold inventories (see Daniel F. Spulber, 1996). ${ }^{32}$

In a network, the link pattern determines the extent to which economies of sharing are realized. For the economies to be fully realized in our three-buyer-two-seller example, there must be enough links so that whichever buyers have the highest two valuations they can always obtain goods. When links are costly, it might not be optimal, from a social welfare point of view, to fully realize the economies of sharing. The gains from adding one more link need not exceed its cost.

We consider efficient link patterns, those that balance the link costs with the expected gains from exchange. Let $W(\mathbf{G})$ denote the net economic surplus from a link pattern $\mathbf{G}$. This net surplus consists of the maximal gross surplus, $H(\mathbf{G})$, minus total link costs. Recall that $H(\mathbf{G})$ is the highest possible surplus from exchange given the link pattern G. It is obtained from the efficient allocation of goods for that link pattern. We have

$$
W(\mathbf{G}) \equiv H(\mathbf{G})-c \sum_{i=1}^{\bar{B}} \sum_{j=1}^{\bar{s}} g_{i j}
$$

where recall $g_{i j}=1$ when buyer $i$ is linked to seller $j$ and $g_{i j}=0$ otherwise. We say a link pattern $\mathbf{G}$ is efficient if it yields the highest net economic surplus of all graphs. ${ }^{33}$

\footnotetext{
${ }^{31}$ If there were three units of capacity and each buyer always purchased a good, the expected surplus from exchange would be $3\left(E X^{1: 1}\right)$; that is, three times the mean of buyers' valuations. If there were only two units of capacity and only the buyers with the top two valuations obtained goods, the expected surplus from exchange would be $E X^{1: 3}$ $+E X^{2: 3}$. While this surplus is smaller than $3\left(E X^{1: 1}\right)$, overall economic welfare may be higher because two units of productive capacity would be less costly than three.

${ }^{32}$ See also Dennis W. Carlton (1978) who assumes that firms must make irreversible decisions before demand uncertainty is resolved.

${ }^{33}$ Below we derive the structure of efficient link patterns using the Marriage Theorem.
} 
Our central question is whether buyers, acting noncooperatively, can form efficient link patterns.

\section{A. A Network Formation Game with Exogenous Sellers}

We consider the following network formation game.

Stage One: Buyers simultaneously choose links to sellers. A buyer incurs a cost $c>0$ for each link. Restricting attention to pure strategies, we describe the links of buyer $i$ by the vector $\mathbf{g}_{i}=\left(g_{i 1}, \ldots, g_{i \bar{S}}\right)$, where $g_{i j}=1$ when buyer $i$ forms a link to seller $j$, and $g_{i j}=0$ otherwise. The buyers' links form a link pattern $\mathbf{G},{ }^{34}$ and we assume $\mathbf{G}$ is observable to all players.

Stage Two: Each buyer $b_{i}$ privately learns its valuation, $v_{i}$, of a good. Buyers compete in the auction specified above. We consider the equilibrium in which buyers bid up to their valuations, and summarize the outcome in buyers' $V$-payoffs. A buyer's final payoff, its profit, is its $V$-payoffs minus its link costs. For $b_{i}$, profits are $\Pi_{i}^{b}(\mathbf{G})=V_{i}^{b}(\mathbf{G})-c \sum_{j=1}^{s} g_{i j}$. For $s_{j}$, profits are $V_{j}^{s}(\mathbf{G})$.

We solve for a perfect Bayesian equilibrium of this game. In the first stage, a buyer's choice of links must maximize its expected profits, given the strategies of other buyers. A buyer cannot have an incentive to add, break, or rearrange any of its links. We say a link profile $\mathbf{G}^{*}$ is an equilibrium strategy profile if and only if for each buyer $b_{i}$

$$
\mathbf{g}_{i}^{*}=\underset{\mathrm{g}}{\arg \max } V_{i}^{b}\left(\mathbf{g}_{i}, \mathbf{g}_{-i}^{*}\right)-c \sum_{j=1}^{\bar{S}} g_{i j} .
$$

\section{B. Efficient Networks and Equilibrium}

We show here our main result: Efficient link patterns are always equilibrium outcomes of the game. The second-stage competition for goods

${ }^{34}$ Again, we can write this link pattern as the $\bar{B} \times \bar{S}$ matrix $\mathbf{G}=\left[g_{i j}\right]$. aligns the incentives of buyers to build links with the social goal of welfare maximization. This result is presented below as Proposition 2 .

The result follows from our assumption that buyers compete for goods. In our model of competition, the resulting allocation of goods is efficient, given the link pattern. The maximal surplus from exchange for the network is achieved. Furthermore, the price a buyer pays is equal to the social opportunity cost of obtaining a good. With these properties, buyers' competitive payoffs are exactly equal to the contribution of their links to economic welfare. That is, if we remove any number of a buyer's links (holding constant the rest of the link pattern), the loss in a buyer's $V$-payoffs is the loss in gross economic surplus. The next example illustrates this outcome. The formal result follows.

Example 5 [Competitive Buyers Earn Social Value of Links]: Consider the link pattern in Figure 3, and suppose buyers' realized valuations are in the order $v_{1}>v_{2}>v_{3}>v_{4}>v_{5}>$ 0 . Let us compare the difference in surplus from exchange and the difference in buyer 3's payoffs if we remove buyer 3's link to seller 3 . With this link, in the efficient allocation and in the auction, buyers 1,3 , and 4 obtain goods, yielding a total surplus of $v_{1}+v_{3}+v_{4}$. Buyer 3 pays a price equal to $v_{5}$, and its payoffs are $v_{3}-v_{5}$. When we remove the link, buyer 5 purchases from seller 3 , buyer 3 purchases from seller 2 , and buyer 4 no longer purchases. The total surplus from exchange is now $v_{1}+v_{3}+$ $v_{5}$, and the reduction in the total surplus is $v_{4}-$ $v_{5}$. Buyer 3 pays a higher price to obtain a good-rather than pay a price of $v_{5}$, it now pays $p=v_{4}$, giving it a payoff of $v_{3}-v_{4}$. The

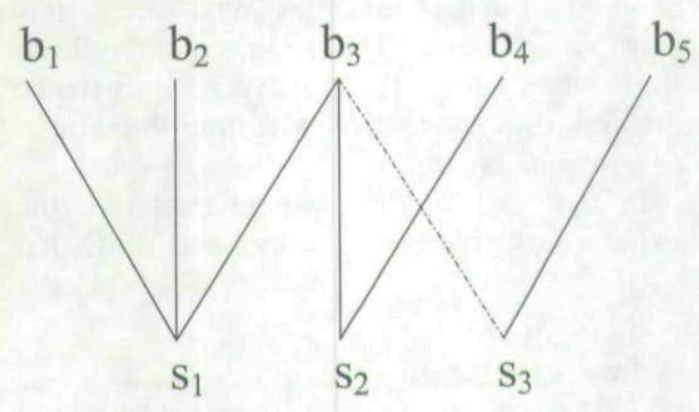

Figure 3. Removing A Link 
reduction in its payoff is $v_{4}-v_{5}$, and this amount is exactly equal to the reduction in total surplus.

Formally, we have:

LEMMA 1: Consider a link pattern G. Remove any number of buyer $i$ 's links to create a new pattern $\mathbf{G}^{\prime}$. The difference in buyer $i$ 's $V$-payoffs is the same as the difference in expected gross surplus: $V_{i}^{b}(\mathbf{G})-V_{i}^{b}\left(\mathbf{G}^{\prime}\right)=$ $H(\mathbf{G})-H\left(\mathbf{G}^{\prime}\right)$. Therefore, $\Pi_{i}^{b}(\mathbf{G})-\Pi_{i}^{b}\left(\mathbf{G}^{\prime}\right)=$ $W(\mathbf{G})-W\left(\mathbf{G}^{\prime}\right)$.

(Appendix B provides proof of this lemma and subsequent results.)

That efficient link patterns are equilibrium outcomes follows directly from this result. Consider any efficient link pattern, ${ }^{35}$ and ask whether any buyer has an incentive to deviate. The answer is no. By keeping its links in place, the buyer makes the largest contribution possible to surplus from exchange, and the buyer earns all this additional surplus in its $V$-payoffs. In an efficient link pattern, this additional surplus exceeds the link costs.

PROPOSITION 2: For any c, each efficient link pattern is an equilibrium outcome of the game.

Proposition 2 shows that when buyers compete for goods, networks can be formed efficiently. This result would hold for any competitive process that yields an efficient allocation of goods and in which buyers' revenues are the marginal surplus from exchange. Moreover, these revenues are not special. When buyers have private information, in order to achieve an efficient allocation of goods, buyers' revenues must satisfy this marginal property. This requirement follows from Myerson's (1981) payoff equivalence theorem. Below we discuss further the robustness of our results.

In the next sections we characterize the structure of efficient networks and show that

\footnotetext{
${ }^{35} \mathrm{We}$ will see later that there are generally several efficient link patterns for each specification of the model's primitives.
}

when link costs are small they are the only equilibrium outcomes of the network formation game.

\section{The Structure of Efficient Networks and a Uniqueness Result}

Efficient link patterns balance the cost of links with ex post gains from exchange. When link costs are small, a network should have enough links so that the buyers with the highest valuations can all obtain goods. All economies of sharing should be realized. In a network with three buyers and two sellers, for example, any set of two buyers should all be able to obtain goods. We say such as network is allocatively complete (AC) and characterize it formally as follows.

Definition 1: A network of buyers and sellers $(\mathbf{B}, \mathbf{S})$ is allocatively complete if and only if for every subset of buyers $\mathcal{B} \subset \mathbf{B}$ of size $\bar{S}$, there is a feasible allocation such that every $b_{i}$ in $\mathcal{B}$ obtains a good.

A network where all the buyers are linked to all the sellers is, obviously, allocatively complete. When $c=0$, this network is efficient. When $c>0$, however, this network is not efficient. As we show next, allocative completeness can be achieved with fewer links.

Least-link allocatively complete (LAC) networks achieve all the economies of sharing with the minimal number of links. Using the Marriage Theorem we show that in these networks each seller has exactly $\bar{B}-\bar{S}+1$ links. We see how these links must be "spread out" so that whichever buyers have the top valuations, there is a feasible allocation in which all these buyers obtain goods. There are many ways to distribute these links among buyers, and some buyers can have more links than others.

PROPOSITION 3: In a LAC network of buyers and sellers $(\mathbf{B}, \mathbf{S})$, each seller is linked to exactly $\bar{B}-\bar{S}+1$ buyers. Each buyer has from 1 to $\bar{S}$ links.

Example 6 [Least-Link Allocatively Complete Networks]: Figure 4 illustrates LAC networks for five buyers and three sellers. Every seller has $\bar{B}-\bar{S}+1=3$ links, as specified in 


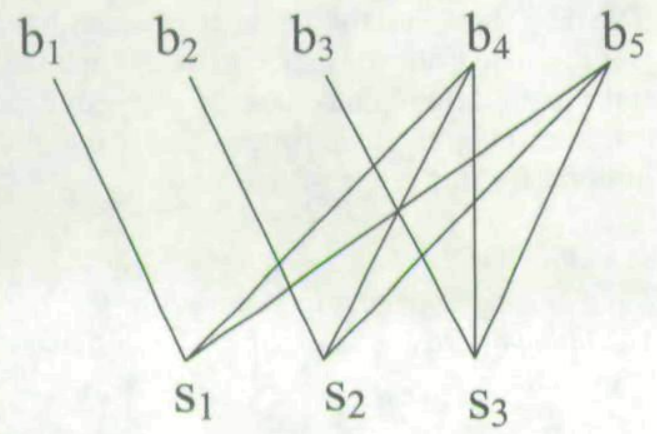

(a)

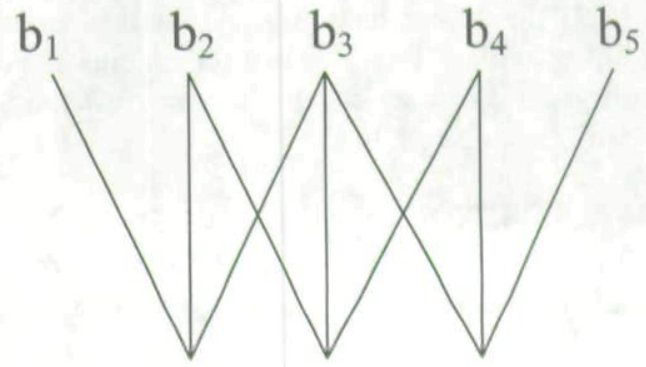

$\mathrm{S}_{1} \quad \mathrm{~S}_{2}$

$\mathrm{S}_{3}$

(b)

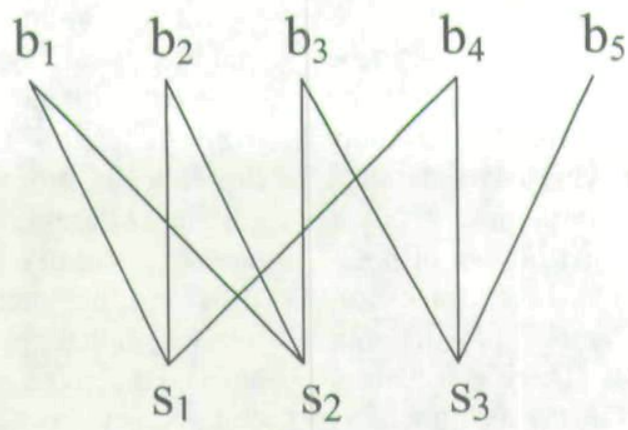

(c)

Figure 4. Least-LinK Allocatively Complete Networks

Proposition 3. The links are "spread out" among the buyers so that whichever three buyers in each network has the highest valuations ex post, there is a feasible allocation in which these three obtain goods. The figure shows that three links per seller is sufficient for allocative completeness. This result is easiest to see in network (a). The first three buyers are each linked to a distinct seller. This set of three buyers can then always obtain goods. The remaining two buyers are each linked to every seller. With these links, the Marriage Theorem is satisfied for any set of three buyers. Therefore, any set of three buyers can always obtain goods. To see that three links per seller is necessary for allocative completeness, consider the possibility (in any of the networks in the figure) that some seller $j$ only has two links. This means that seller $j$ is not linked to three buyers. When these particular three buyers have the top valuations, they cannot all obtain goods, and the network is not allocatively complete. Note that there is more than one way for sellers' links to be placed. Buyers may have different numbers of links. From the point of view of social welfare, however, there is no distinction between these networks.

We identify a range of small link costs where LAC networks are the efficient networks. For these costs, all economies of sharing should be realized. In a network where some set of $\bar{S}$ buyers cannot all obtain goods, there is a loss in gross surplus of at least $\left(\frac{\bar{B}}{S}\right)^{-1} E\left[X^{\bar{S}: \bar{B}}-\right.$ $\left.X^{\bar{S}+1: \bar{B}}\right]$. With probability $\left(\frac{\bar{B}}{\bar{S}}\right)^{-1}$, these $\bar{S}$ buyers 
have the top valuations, and in this event a buyer with a lower valuation obtains a good instead. We show we can eliminate such a loss with exactly one link.

PROPOSITION 4: If $0<c \leq\left(\frac{\bar{B}}{S}\right)^{-1} E\left[X^{\bar{S}: \bar{B}}-\right.$ $\left.X^{\bar{S}+1: \bar{B}}\right]$, then LAC networks of buyers and sellers $(\mathbf{B}, \mathbf{S})$ are the efficient networks.

Before returning to our network formation game, we discuss some interesting features of the structure of efficient networks. First, LAC networks serve as a benchmark for all efficient networks. For high link costs, efficient link patterns involve fewer links. It is not optimal to realize all the economies of sharing. Allocations of goods are constrained, and the networks yield lower gross welfare than do LAC's.

Second, in efficient networks buyers can be in very asymmetric positions (while sellers are in relatively symmetric positions). This may seem surprising because buyers have identical demand and production technologies. A buyer with many links bears a greater burden of pooling demand uncertainty. In an LAC, for example, all buyers have the same $V$-payoffs, but some have higher link costs. There is a natural economic interpretation of these asymmetries. Consider the network (a) in Figure 4. Buyers 1, 2 , and 3 are each linked to just one seller, while buyers 4 and 5 are each linked to all three sellers. We can think of buyers with one link as "primary customers" of their respective sellers and of the other buyers as "secondary customers." Indeed, the probability that a seller sells its good to its primary buyer is $\bar{S} / \bar{B}$ while the probability that it sells to one of its secondary buyers is only $1 / \bar{B}$.

These asymmetries highlight our result that every efficient network is an equilibrium. No matter how asymmetric are buyers' profits, a buyer with many links is willing to invest in these links because his $V$-payoff incorporates their value to economic welfare. Given the link holdings of the other buyers, this is the best the buyer can do. ${ }^{36}$

\footnotetext{
${ }^{36}$ An interesting direction for future research would be to explore how buyers compete for these different positions in a network. Consider sequential link investments by buyers. By investing early, a buyer might be able to establish itself as a primary customer.
}

We next show that for the range of small link costs discussed above, LAC networks are the unique equilibrium outcomes of the game. ${ }^{37}$ Therefore, efficient link patterns are the only equilibria for this range of link costs.

PROPOSITION 5: For $0<c \leq\left(\frac{\bar{B}}{s}\right)^{-1} E\left[X^{\bar{S}: \bar{B}}-\right.$ $\left.X^{\bar{S}+1: \bar{B}}\right]$, only efficient link patterns, that is, LAC link patterns, are equilibrium outcomes of the game.

For this range of link costs, some buyer has an incentive to add or break a link in any network that is not LAC. There are two types of non-LAC networks to consider. First, the network could be allocatively complete, but with more links than an LAC. In this case, a buyer would have an incentive to cut a link. We show that there is always at least one link that can be removed with no change in the gross surplus from exchange. ${ }^{38}$ By Lemma 1, if the buyer cuts this link, its profits increase exactly by $c$, the gain in welfare. For $c>0$, then, a buyer would have an incentive to cut this "redundant" link.

Second, the network might not be allocatively complete. In this case, some buyer would have an incentive to add a link. We know that in non-AC networks, there is some set of $\bar{S}$ buyers that cannot all obtain goods. When these buyers have the top valuations, at least one of them will not obtain a good, even though it values a good more than other buyers. We show that it is possible for at least one buyer to add a link and obtain a good in this event, when it would not otherwise. Importantly, the buyer can achieve this greater access to goods without any change in other buyers' links. The buyer earns a gain in revenues of at least $\left(\frac{\bar{B}}{\bar{S}}\right)^{-1} E\left[X^{\bar{S}: \bar{B}}-X^{\bar{S}+1: \bar{B}}\right]$. Since a buyer's gain in revenues is exactly equal to its contribution to economic surplus, it is also efficient for a buyer to add this link.

\section{Discussion of Efficiency Results}

We discuss briefly here the robustness of our equilibrium results. Efficient networks would be

\footnotetext{
${ }^{37}$ Although there may be several LAC link patterns, the equilibrium is unique in the sense that every equilibrium outcome involves an LAC pattern.

${ }^{38}$ That is, we show that for every AC network, there is an LAC network that is a subgraph.
} 
equilibrium outcomes for any model of competition that yields an efficient allocation of goods and where buyers earn the marginal surplus from exchange. Models of competition that do not share these features, however, could lead to inefficient networks.

First, in a setting where competition does not yield an efficient allocation of goods, the reduction in surplus would lead to suboptimal investment in links. Depending on the features of competition, more subtle distortions in incentives might also be associated with allocation inefficiencies. ${ }^{39}$ However, absent time delays or other frictions, we posit that any reasonable model of competition should yield an efficient allocation of goods. Otherwise, some buyer and seller could renegotiate the allocation and terms of trade to their mutual benefit. ${ }^{40}$

Second, if buyers receive less than the full marginal value of an exchange, they could have insufficient incentives to invest in links. Setting aside the problem of achieving an efficient allocation, a priori, there could be any split of the marginal surplus from an exchange. In general, when the split of surplus is less than the share of investment, there would be underinvestment in links. This suggests an efficiency argument that the split of surplus should match the investment environment. The division of the surplus in the auction fits our investment environment because buyers bear the entire cost of links.

We next consider a more complex network formation game, where both sellers and buyers make investments in the network.

\section{Network Formation with Endogenous Sellers}

In this section we study network formation when productive capacity is costly and the set of sellers that invest in capacity is endogenous. We develop a network formation game, define efficient networks, and analyze equilibrium outcomes. We identify two reasons why networks

\footnotetext{
${ }^{39}$ Buyers may build extra links to affect their bargaining position, for example.

${ }^{40}$ Another future direction for research would be to characterize network outcomes when sellers also have private information over costs. In this case, no trading mechanism can always yield efficient allocations (Myerson and Mark A. Satterthwaite, 1983).
}

may be formed inefficiently in this more complex environment.

\section{A. The Game with Sellers' Investments}

Stage One: Buyers simultaneously choose links to sellers and incur a cost $c>0$ per link. As before, let $\mathbf{g}_{i}=\left(g_{i 1}, \ldots, g_{i \bar{S}}\right)$ denote buyer $i$ 's strategy, and let $\mathbf{G}$ denote the link pattern. When buyers choose links, sellers simultaneously choose whether to invest in assets that $\operatorname{costs} \alpha>0$. This asset allows it to produce one indivisible unit of a good at zero marginal cost for any linked buyer. A seller that does not invest cannot produce. Let $z_{j}=1$ indicate seller $j$ invests in an asset and $z_{j}=0$ when seller $j$ does not invest, where $\mathbf{Z}=\left(z_{1}, \ldots, z_{\bar{S}}\right)$ denotes all sellers' investments. The investments $(\mathbf{G}, \mathbf{Z})$ are observable at the end of the stage. ${ }^{41}$

Stage Two: Each buyer $b_{i}$ privately learns its valuation $v_{i}$. Buyers compete for goods in the auction constructed above. As before, we consider the equilibrium in the auction in which buyers bid up to their valuations. An agent's profits are its $V$-payoff minus any investment costs. For $b_{i}$, profits are $V_{i}^{b}(\mathbf{G}, \mathbf{Z})-c \sum_{j=1}^{\bar{S}}$ $g_{i j}$. For a seller $j$, profits are $V_{j}^{s}(\mathbf{G}, \mathbf{Z})-\alpha$ if it has invested in an asset. Profits are zero for all other sellers.

As previously, we solve for a pure-strategy perfect Bayesian equilibria. Given other agents' investments, a buyer invests in its links if and only if no other choice of links generates a higher expected profit. A seller invests in capacity if and only if it earns positive expected profit.

\section{B. Efficiency and Equilibrium}

Efficient networks allow the highest economic welfare from investment in links, productive

\footnotetext{
${ }^{41}$ To derive the link pattern that results from players' investments, it is convenient to write the sellers' investments as $\bar{S} \times \bar{S}$ diagonal matrix $\mathbf{Z}$, where $z_{i i}=1$ if seller $i$ has invested, $z_{i i}=0$ otherwise (and $z_{i j}=0$ for $i \neq j$ ). The link pattern at the end of stage one will then be $\mathbf{G} \cdot \mathbf{Z}$. In equilibrium, since links are costly, a buyer will not build a link to a seller that does not invest, and we will have $\mathbf{G}$. $\mathbf{Z}=\mathbf{G}$.
} 
assets, and exchange of goods. The net economic surplus from a network, $W(\mathbf{G}, \mathbf{Z})$, is the gross economic surplus minus the investment and link costs: $W(\mathbf{G}, \mathbf{Z}) \equiv H(\mathbf{G}, \mathbf{Z})-$ $c \sum_{i=1}^{\bar{B}} \sum_{j=1}^{\bar{S}} g_{i j}-\alpha \sum_{j=1}^{\bar{S}} z_{j}$. A network is an efficient network if and only if no other network yields higher net economic surplus.

In contrast to our previous game, here the efficient network is not always an equilibrium outcome. Buyers' incentives are aligned with economic welfare, but sellers sometimes have insufficient incentives to invest in assets. A seller's investment is efficient whenever its cost, $\alpha$, is less than what it generates in expected surplus from exchange. The price a seller receives, however, is less than the surplus from exchange. As discussed above, the price is not equal to the purchasing buyer's valuation but to the valuation of the "nextbest" buyer. Each seller's profit, therefore, is less than its marginal contribution to economic welfare.

The next example illustrates that there is a divergence between efficiency conditions and sellers' investment incentives when sellers' costs are high. When $\alpha$ is sufficiently low, the efficient network is an equilibrium outcome. But when $\alpha$ is high enough, sellers will not invest.

\section{Example 7 [Sellers' Investment Incentives]:} Consider the LAC networks in Figure 4. In these networks the buyers with the top three valuations always obtain goods. They are efficient if the valuation of the thirdhighest buyer justifies the link and investment costs; that is, if $\alpha+3 c \leq E\left[X^{3: 5}\right]$ and $c \leq$ $\left(\begin{array}{l}5 \\ 3\end{array}\right)^{-1} E\left[X^{3: 5}-X^{4: 5}\right]{ }^{42}$ In these networks, each seller always receives a price of $X^{4: 5}$, since at this price the supply of three units equals the demand for three units. Each seller's profit is then $E\left[X^{4: 5}\right]-\alpha$, and a seller will invest if and only if $\alpha \leq E\left[X^{4: 5}\right]$. It is easy to see that efficiency conditions for these networks diverge from the sellers' investment incentives. When $c=0$, to take an extreme case, the networks are efficient for $\alpha \leq E\left[X^{3: 5}\right]$. Sellers will invest in assets

\footnotetext{
${ }^{42} \mathrm{~A}$ proof available upon request shows that, in general, a sufficient condition for an LAC network with $\bar{B}$ buyers and $\bar{S}$ sellers to be efficient is that $(c, \alpha)$ be such that $\alpha+(\bar{B}-\bar{S}+$ 1) $c \leq E\left[X^{\bar{S} \cdot \bar{B}}\right]$ and $c \leq\left(\frac{\bar{B}}{S}\right)^{-1} E\left[X^{\bar{S}: \bar{B}}-X^{\bar{S}+1: \bar{B}}\right]$.
}

when $\alpha \leq E\left[X^{4: 5}\right]$, but not when $E\left[X^{3: 5}\right] \geq$ $\alpha \geq E\left[X^{4: 5}\right]$.

The problem of covering sellers' costs is a consequence of the private information and contractual incompleteness in our environment. ${ }^{43}$ We have assumed that no payments from buyers to sellers are determined until the second stage of the game, after buyers realize their valuations for goods. To cover their costs at this point, sellers could charge a fixed fee or (equivalently) set a reserve price in their auctions. But, since buyers' valuations are private information, any such fee would lead to an inefficient allocation of goods. ${ }^{44}$ Buyers with low realized values will not pay the fee; for some realizations of buyers' valuations, goods will not be sold. Therefore, in our setting, there is either an inefficiency in the allocation of goods (which would distort buyers' investment incentives) or some underinvestment on the part of the sellers when sellers' investment costs are high.

Coordination failure is a second source of inefficiency in this game. When both buyers and sellers make investment decisions, there are many equilibria where not enough investment takes place. The intuition is simple. Sellers invest in assets only if they expect enough future demand so that they can cover their investment costs. Buyers only establish links to sellers if they expect the sellers to invest. Therefore, the possibility arises that some sellers do not invest because they do not have links to a sufficient number of buyers, and buyers do not build links

\footnotetext{
${ }^{43}$ It would always be possible to cover sellers' costs if long-term contracts were available. Buyers could commit to pay sellers for their investments regardless of which buyers ultimately purchase goods. Such agreements, however, are likely to be difficult to enforce or violate antitrust law. These payments might also be difficult to determine. As we have seen, buyers can be in very asymmetric positions in efficient networks, and the payments may need to reflect this asymmetry. The more complex the fees need to be, and the more buyers and sellers need to be involved, the less plausible are long-term contracts.

${ }^{44}$ This result again follows from the payoff equivalence theorem (Myerson, 1981). Since buyers have private information, for an efficient allocation of goods buyers must earn the marginal surplus of their exchange, plus or minus a constant ex ante payment. That is, buyers must be bound to make the payment regardless of their realized valuations.
} 
to these sellers because they do not invest. Indeed, the null network is always an equilibrium of this model.

Such coordination failures may be preventable, of course, in an expanded model of network formation. For example, if buyers and sellers can engage in discussions or "cheap talk" prior to investment, they may be able to coordinate on the efficient network without any formal contracting. ${ }^{45}$ Indeed, professional associations, chambers of commerce, and other institutions that foster business relations may facilitate this coordination. ${ }^{46}$

\section{Conclusion}

This paper addresses two fundamental economic questions: First, what underlying economic environment may lead buyers and sellers to establish links to multiple trading partners? That is, why do networks, which we see in a variety of settings and industries, arise? Second, should we expect such networks to be efficient? Can buyers and sellers, acting noncooperatively in their own self-interest, build the socially optimal network structure?

Our answer to the first question is that networks can enable agents to pool uncertainty in demand. When sellers' productive capacity is costly and buyers have uncertain valuations of goods, it is socially optimal for buyers to share the capacity of a limited number of sellers. The way in which buyers and sellers are linked, however, plays a critical role in realizing these economies of sharing. Because links are costly, there is a trade-off between building links and pooling risk. Using combinatoric techniques, we show that the links must be "spread out" among the agents and characterize the efficient link patterns which optimize this trade-off.

${ }^{45}$ For an overview of the cheap talk literature, see Farrell and Matthew Rabin (1996). Cheap talk can improve coordination, but it can also have no effect at all depending on which equilibrium is selected. Another way to solve coordination failure is for the agents to invest sequentially with buyers choosing links in advance of sellers choosing assets. This specification, however, introduces more subtle coordination problems as discussed in Kranton and Minehart (1997).

${ }^{46}$ See, for example, Lazerson (1993) who describes the voluntary associations and government initiatives that helped establish the knitwear districts in Modena, Italy.
We then address the second question: When can buyers and sellers, acting noncooperatively, form the efficient network structure? A priori there is no reason to expect that buyers will have the "correct" incentives to build links, and sellers the correct incentives to invest in productive capacity. We identify properties of the ex post competitive environment that are sufficient to align buyers' incentives with social welfare. First, the allocation of goods is efficient. Second, the buyer earns the marginal surplus from exchange, and thus, the value of its links to economic welfare. However, it is also possible that sellers may not receive sufficient surplus to justify efficient investment levels. And buyers and sellers may fail to coordinate their link and investment decisions.

We find evidence for our positive results in studies of industrial-supply networks. In many accounts, buyers are aware of the potential consequence for their suppliers of uncertainty in their demand. Buyers share suppliers, explicitly to ensure that suppliers have sufficiently high demand to cover investment costs. Buyers "spread out" their orders-reflecting the structure of efficient link patterns. In a study of engineering firms and subcontracting in France, we find a remarkably clear description of this phenomenon. According to Lorenz (1989), buyers keep their orders between $10-15$ percent of a supplier's sales. This " $10-15$ percent rule" is explained as follows: "The minimum is set at 10 percent because anything less would imply a too insignificant a position in the subcontractor's order book to warrant the desired consideration. The maximum is set at 15 percent to avoid the possibility of uncertainty in the [buyer's] market having a damaging effect on the subcontractor's financial position...." (p. 129).

In another example, Nishiguchi's (1994) study of the electronics industry in Japan reveals that buyers counter the problem of "erratic trading" with their subcontracters by spreading orders among the firms, warning their contracters of shortfalls in demand, and even asking other firms to buy from their subcontracters when they have a drop in orders. In an interview, a buyer explains: "We regard our subcontractors as part of our enterprise group... . Within the group we try to allocate the work evenly. If a subcontractor's workload is down, we help him find a new job. Even if we have to cut off 
our subcontractors, we don't do it harshly. Sometimes we even ask other large firms to take care of them" (p. 175). These practices are part of longterm economic calculation to maintain a subcontractor's investment in value-enhancing assets. ${ }^{47}$

There is also evidence of our less optimistic results: firms may fail to coordinate on the efficient network structure, or even in establishing any links at all. In many developing countries, there is hope that local small-scale industries can mimic the success of European vertical supply networks. However, researchers have found that firms do not always coordinate their activities (John Humphrey, 1995). There is then a role for community and industry organizations, such as chambers of commerce, in establishing efficient networks.

By introducing a theory of link patterns, this paper opens the door to much future research on buyer-seller networks. Here we have explored one economic reason for networks: economies of sharing. There are many other reasons why multiple links between buyers and sellers are socially optimal. Buyers may want access to a variety of goods. Sellers may have economies of scope or scale. Sellers could be investing in different technologies, and buyers may want to maintain relationships with many sellers to benefit from these efforts. In many environments, a firm's gain from adopting a technology may depend on the number of other firms adopting the technology. Using the model here, a buyer's adoption of a seller's technology can be represented by a "link," allowing a more precise microeconomic analysis of "network externalities" and "systems competition." Future studies of networks may give other content to the links. Links to sellers or buyers may contain information about product-market trends, or even competitors. There may then be a trade-off between gathering information and revealing information by establishing links.

Future research on networks could build on to the bipartite structure introduced here. For example, in addition to the links between buyers and sellers, there may be links between the sellers themselves (or between the buyers them-

\footnotetext{
${ }^{47}$ For more evidence of the need for suppliers to serve several buyers, see, for example, Cawthorne (1995 p. 48) and Roberta Rabellotti (1995 p. 37).
}

selves). These links could represent a sellers' cooperative or industry group. There are many settings where sellers, formally and informally, share inventories and otherwise cooperate to increase their collective sales. ${ }^{48}$ In another example, a product market could be added to the buyer side of the network. In industrialsupply settings, the buyers could be manufacturers that in turn sell output to consumers. We could then ask how the nature of consumers' demand and the final product market affect network structure,

This paper suggests a new, network approach to the study of personalized and group-based exchange. A growing literature shows how long-term, personalized exchange can shape economic transactions. Greif (1993) studies the eleventh-century Maghribi traders who successfully engaged in long-distance commerce by hiring agents from within their group. Kranton (1996) shows how exchange between friends and relatives and the use of "connections" supplants anonymous market exchange in many settings. The analysis here suggests a link-based strategy for evaluating such forms of exchange and interlocking groups of buyers and sellers. In our study of efficient link patterns, for example, we saw that all agents need not be linked to all other agents. Sparse links between agents or across groups, then, may not be evidence of trading inefficiencies. The pattern may also reflect the optimal trade-off between the cost of links and the potential gains from exchange.

\section{APPENDIX A: COMPETITION FOR GOODS IN Buyer-Seller Networks: AN Auction MOdel}

In this Appendix, we develop our ascendingbid auction model of competition in networks. We first show that it is possible to construct, in a network, a process of "auction clearing" that is well-defined. We then construct the auction game and show that it is an equilibrium following iterated elimination of weakly dominated strategies for each buyer to remain in the bidding of each linked seller's auction up to its valuation of a good. This argument requires a

\footnotetext{
${ }^{48}$ For instance, we have seen this phenomenon among jewelry retailers-in San Francisco's Chinatown, Boston's Jewelry Market, and the traditional jewelry district in Rabat, Morocco.
} 
proof beyond that for a single-seller ascendingbid auction. A priori we might think a buyer could gain by dropping out of some auctions at a price below its valuation. The auction could clear at a lower price, and fewer buyers would be bidding in remaining auctions. The buyer could then procure a good at a lower price. The proof shows this reasoning is false. We end the Appendix by proving Proposition 1 . In the equilibrium, (i) the allocation is efficient, and (ii) the allocation and prices are pairwise stable.

First, make precise what we mean by "demand is weakly less than supply" for a subset of sellers in a network. The auction will specify that whenever this situation occurs, this subset of sellers will "clear" at the going price.

As the auction proceeds, there will be interim link patterns that reflect whether buyers are still actively using their links to secure goods. Starting from any link pattern, when a buyer drops out of the bidding of an auction, we can think of it as no longer linked to that seller. Similarly, when a buyer secures a good, it is effectively no longer linked to any remaining seller.

In these interim patterns, we will ask whether any subset of sellers is clearable. Formally, consider any link pattern $\mathbf{G}$. A subset of sellers $C$ is clearable if and only if there exists a feasible allocation such that all buyers $b_{i} \in$ $L(C)$ obtain a good from a seller $s_{j} \in C$. (Note that, by definition, for a clearable set of sellers $C$, total demand is weakly less than supply (i.e., $|L(C)| \leq|C|)$.

We use Lemma Al to show that there is always a unique maximal clearable set of sellers. This set, denoted by $\mathbf{C}$, is the union of all clearable sets of sellers in a given "interim" link pattern. If there are no clearable sets, $\mathbf{C}=\varnothing$.

LEMMA A1: Consider two clearable sets of sellers $C^{\prime}$ and $C^{\prime \prime}$. The set $\left\{C^{\prime} \cup C^{\prime \prime}\right\}$ is also a clearable set of sellers.

\section{PROOF:}

If $C^{\prime}$ and $C^{\prime \prime}$ are disjoint, then clearly the union is a clearable set. For the case when they are not disjoint, the first task is to show that

$$
\left|L\left(C^{\prime} \cup C^{\prime \prime}\right)\right| \leq\left|C^{\prime}\right|+\left|C^{\prime \prime}\right|-\left|C^{\prime} \cap C^{\prime \prime}\right| .
$$

That is, the number of buyers linked to the sellers in $C^{\prime} \cup C^{\prime \prime}$ does not exceed the number of sellers in that set. To show this, we will add up the buyers from linked buyers of each subset and show that the sum cannot exceed $\left|C^{\prime}\right|+$ $\left|C^{\prime \prime}\right|-\left|C^{\prime} \cap C^{\prime \prime}\right|$.

Because $C^{\prime}$ is a clearable subset, by definition $\left|L\left(C^{\prime}\right)\right| \leq\left|C^{\prime}\right|$. Consider $L\left(C^{\prime} \cup C^{\prime \prime}\right)$. How many buyers are in this set? First of all, we have the buyers in $L\left(C^{\prime}\right)$. Now we add buyers from $L\left(C^{\prime \prime}\right)$. We add those buyers that are in $L\left(C^{\prime \prime}\right)$, but not in $L\left(C^{\prime}\right)$. The largest number of buyers that we can add is $\left|C^{\prime \prime}\right|-\left|C^{\prime} \cap C^{\prime \prime}\right|$. Why? We cannot add any buyers that are linked to the sellers in $\left\{C^{\prime} \cap C^{\prime \prime}\right\}$ because they have already been counted as part of $L\left(C^{\prime}\right)$. So we can only add buyers that are linked exclusively to the remaining sellers in $C^{\prime \prime}$, which number $\left|C^{\prime \prime}\right|-$ $\left|C^{\prime} \cap C^{\prime \prime}\right|$. At most $\left|C^{\prime \prime}\right|-\left|C^{\prime} \cap C^{\prime \prime}\right|$ buyers are linked exclusively to these sellers. If there were more than this number of buyers exclusively linked to these sellers, the Marriage Theorem would be violated for $C^{\prime \prime}$, that is, there would be a subset $k$ of the buyers in $L\left(C^{\prime \prime}\right)$ that are collectively linked to less than $k$ sellers. So we have

$$
\left|L\left(C^{\prime} \cup C^{\prime \prime}\right)\right| \leq\left|L\left(C^{\prime}\right)\right|+\left|C^{\prime \prime}\right|-\left|C^{\prime} \cap C^{\prime \prime}\right|
$$

which shows that the inequality above is satisfied.

Next, we show that there exists a feasible allocation in which all the buyers in $L\left(C^{\prime} \cup C^{\prime \prime}\right)$ obtain goods. Assign the buyers in $L\left(C^{\prime}\right)$ to sellers in $C^{\prime}$. This is possible because $C^{\prime}$ is a clearable set. Assign the additional $\left|C^{\prime \prime}\right|-\mid C^{\prime}$ $\cap C^{\prime \prime} \mid$ (or less) buyers from $L\left(C^{\prime \prime}\right)$ to sellers in the set $\left\{C^{\prime \prime} \backslash\left(C^{\prime} \cap C^{\prime \prime}\right)\right\}$. This is possible because these buyers are exclusively linked to sellers in $\left\{C^{\prime \prime} \backslash\left(C^{\prime} \cap C^{\prime \prime}\right)\right\}$ and $C^{\prime \prime}$ is a clearable set-every subset of $k$ buyers must be collectively linked to at least $k$ sellers and thus all are able to secure goods.

We now construct the auction game. First, sellers simultaneously decide whether or not to hold ascending-bid auctions as specified below. This choice is observed by all players. Sellers make no other decisions. (E.g., they cannot set reserve prices. We discuss the implications of reserve prices in the text.) Auctions of participating sellers proceed as follows: There is a common price across all auctions. Buyers can 
bid only in auctions of sellers to whom they are linked. Initially, all buyers are active at a price $p=0$. The price rises. At each price, each buyer decides whether to remain in the bidding or drop out of each auction. Once a buyer drops out of the bidding of an auction, it cannot reenter that auction at a later point in time. Buyers observe the history of the game.

The price rises until a clearable set of sellers occurs in an interim link pattern. The buyers that are linked to the sellers in the maximal clearable set, $L(\mathbf{C})$, secure a good at the current price. If there is more than one feasible allocation where all $b_{i} \in L(\mathbf{C})$ obtain goods, but where different sellers provide goods, one feasible allocation is chosen at random. Note that this rule implies no buyer is ever allocated more than one good. Removing these sellers and their buyers from the network creates another interim link pattern. If there are remaining sellers, the price continues to rise until another clearable set arises in further "interim" link patterns. This procedure continues until there are no remaining bidders.

In this game, a strategy for a seller is simply a choice whether or not to hold an auction. A strategy for a buyer $i$ specifies the auctions in which it will remain active at any price level $p$, as a function of $v_{i}$, any remaining sellers, any remaining buyers, any interim link pattern, and any prices at which any buyers dropped out of the bidding of any auctions.

We solve for a perfect Bayesian equilibrium following iterated elimination of weakly dominated strategies. It is a weakly dominant strategy for a seller to hold an auction since it earns nothing if it does not. For buyers, we have the following result.

PROPOSITION A1: For a buyer, the strategy to remain in the bidding of each of its linked sellers' auctions up to its valuation of a good is an equilibrium following iterated elimination of weakly dominated strategies.

\section{PROOF:}

We do not consider the possibility that two buyers have the same valuation. This is a probability-zero event, and we are interested only in expected payoffs from the auction.
1. First we argue that the proposed strategy constitutes a perfect Bayesian equilibrium. Does any buyer have an incentive to deviate from the above strategy? Clearly, no buyer would have an incentive to stay in the bidding of an auction after the price exceeds its valuation. But suppose that for some history of the game, a buyer $i$ drops out of the auction of some linked seller $s_{j}$ when the price reaches $\tilde{p}<v_{i}$. The buyer's payoff can only increase from the deviation if the buyer obtains a good, so we will assume that this is the case. Let seller $h$ be the seller from whom buyer $i$ obtains a good after it deviates.

We argue that the buyer cannot lower the price it pays for a good by dropping out of an auction early. There are two cases to consider:

(i) Buyer $i$ obtains a good from seller $h$ at the price $\tilde{p}$. We argue that this outcome can never arise. Consider the maximal clearable set of sellers, $\mathbf{C}$, and the set of buyers that obtain goods from these sellers $\bar{L}(\mathbf{C})$ at price $\tilde{p}$, given buyer $i$ drops out of seller $j$ 's auction at price $\tilde{p}$. Since buyer $i$ obtains a good, we have $b_{i} \in \bar{L}(\mathbf{C})$. At some price just below $\tilde{p}$ (just before buyer $i$ drops out) the set $L(\mathbf{C})$ is exactly the same. Hence, if $\mathbf{C}$ is a clearable set at $\tilde{p}$ it is also a clearable set at the lower price.

(ii) Buyer $i$ obtains a good from seller $h$ at a price above $\tilde{p}$. Consider the buyer that drops out of the bidding so that the auction of $s_{h}$ clears. Label this buyer $b^{\prime}$ and its valuation $v^{\prime}$. Buyer $i$ pays seller $h$ the price $v^{\prime}$. Let $S$ denote the set of sellers that clear at any price weakly below $v^{\prime}$. Seller $h$ is in this set. Consider the set of buyers linked to at least one seller in $S$ in the original graph; we denote these buyers $L(S)$. We can divide into $L(S)$ into two subsets: those buyers that obtain a good at a price weakly below $v^{\prime}$, and those that drop out of the bidding at some prices weakly below $v^{\prime}$. Every buyer in the second group drops out of the bidding because it has a valuation below $v^{\prime}$. Buyers in the first group obtain their goods from sellers in $S$, because by 
definition all sellers whose auctions clear by $v^{\prime}$ are in $S$.

Now consider the equilibrium path, where buyer $i$ does not drop out early from seller $j$ 's auction. Consider the allocation of goods from sellers in $S$ to buyers in $L(S)$ from the previous paragraph. Any buyer in $L(S)$ that does not obtain a good has a valuation below $v^{\prime}$. Using this allocation, we could "clear" $S$ at the price $v^{\prime}$. It follows that the sellers in $S$ clear at or before the price $v^{\prime}$. Since buyer $i$ is in $L(S)$, buyer $i$ obtains a good at a price weakly below $v^{\prime}$. That is, buyer $i$ gets a weakly lower price on the equilibrium path.

To see that a buyer can never decrease the price it pays by dropping out of several auctions, simply order the auctions by the price at which the buyer drops out from lowest to highest and apply the above argument to the last auction. (The argument works unchanged if a buyer drops out of several auctions at once.)

2. We now show that the proposed strategies are an equilibrium following iterated elimination of weakly dominated strategies.

First, suppose that each buyer $i$ chooses a bidding strategy that depends only on its own valuation $v_{i}$ and not on the history of the game. That is, buyer $i$ 's strategy is to stay in the bidding of auction $j$ until the price reaches $b_{i}\left(v_{i}, j\right)$. The same argument as in part 1 shows that it is a weak best response for each buyer to stay in the bidding of all auctions until the price reaches its valuation. In the parts of the argument above where a buyer $k$ 's valuation $v_{k}$ determines the price at which an auction clears, replace the buyer's valuation with the price from the bidding strategy $b_{k}\left(v_{k}, j\right)$.

Second, suppose that buyers choose strategies that depend on the history of the game. These strategies specify that, for some histories, buyers will drop out of some auctions before the price reaches their valuations and/or remain in some auctions after the price exceeds their valuations. There are only two reasons for a buyer $i$ to adopt such a strategy. First, by dropping out of an auction early, a $b_{i}$ allows another buyer $k$ to purchase a good from $s_{j}$ and thereby lowers the price $b_{i}$ ultimately pays for a good. We showed above that this reduction never occurs. Second, dropping out of an auction early or staying in an auction late may lead to a response by other buyers. Consider any play of the game in which, as a consequence of buyer $i$ dropping out, some other buyers no longer remain in all auctions until the price reaches their valuation or stay in an auction after the price exceeds their valuation. Since the population of buyers is finite, there are only a finite number of buyers who would bid in this way. Consider the last such buyer. When it bids in this way, the buyer does not affect the bidding of any other buyers. Therefore, it can only lose by adopting the strategy to drop out of an auction before the price reaches its valuation, or remain in an auction after the price exceeds its valuation. This strategy is weakly dominated by staying in each auction exactly until the price reaches its valuation. Eliminating this strategy, the second-to-last buyer's strategy to drop out early or remain late is then also weakly dominated. And so on.

We finish our treatment of the auction by proving Proposition 1: (i) in this equilibrium of the auction, the allocation of goods is efficient for any realization of buyers' valuations $\mathbf{v}$, and (ii) the allocation and prices are pairwise stable.

\section{PROOF OF PROPOSITION 1:}

(i) We show that in equilibrium, the highestvaluation buyers obtain goods whenever possible given the link pattern. Therefore, the equilibrium allocation of goods is efficient for any realization of buyers' valuations $\mathbf{v}$.

At the price $p=0$ and the original link pattern, consider any maximal clearable set of sellers, $\mathbf{C}$, and the buyers in $L(\mathbf{C})$. It is trivially true that these buyers have the highest valuations of buyers linked to sellers in $\mathbf{C}$ in the original link pattern.

Now consider the remaining buyers $\mathbf{B} \backslash L(\mathbf{C})$, the interim link pattern that arises when the set $\mathbf{C}$ is cleared, and the next maximal clearable set of sellers, $\mathbf{C}^{\prime}$, that arises at some price $p>0$. We let $L\left(\mathbf{C}^{\prime}\right)$ 
denote the set of buyers linked to any sellers in $\mathbf{C}^{\prime}$ in the interim link pattern. By definition of a clearable set, $\left|L\left(\mathbf{C}^{\prime}\right)\right| \leq\left|\mathbf{C}^{\prime}\right|$, but for $p>0$, it can be shown that $\left|L\left(\mathbf{C}^{\prime}\right)\right|$ $=\left|\mathbf{C}^{\prime}\right|{ }^{49}$ Consider the buyers in $L\left(\mathbf{C}^{\prime}\right)$. We argue that these buyers must have the highest valuations of the buyers in $\mathbf{B} \backslash L(\mathbf{C})$ linked to any seller in $\mathbf{C}^{\prime}$ in the original link pattern. Suppose not. That is, suppose there is a buyer $b_{i} \in \mathbf{B} \backslash L(\mathbf{C})$ that was linked to a seller in $\mathbf{C}^{\prime}$ in the original graph and has a higher valuation than some buyer in $L\left(\mathbf{C}^{\prime}\right)$. For $b_{i}$ not to be in $L\left(\mathbf{C}^{\prime}\right)$, it either obtained a good from a seller in $\mathbf{C}$ or it dropped out of the auction at a lower price. The first possibility contradicts the assumption that $b_{i} \in \mathbf{B} \backslash L(\mathbf{C})$. The second possibility contradicts the equilibrium strategy. So any buyer in $\mathbf{B} \backslash L(\mathbf{C})$ with a higher valuation than some buyer in $L\left(\mathbf{C}^{\prime}\right)$ was not linked to any seller in $\mathbf{C}^{\prime}$ in the original link pattern. Thus, the $\left|\mathbf{C}^{\prime}\right|$ buyers that obtain goods from the sellers in $\mathbf{C}^{\prime}$ are the buyers with the highest valuations of those linked to the sellers in $\mathbf{C}^{\prime}$ in the original link pattern who are not already obtaining goods from other sellers. And so on, for the next maximal clearable set of sellers $\mathbf{C}^{\prime \prime}$.

(ii) We show here that the allocation and prices are pairwise stable. Suppose a seller $j$ sells its good to buyer $k$ and in the original graph seller $j$ is linked to a buyer $i$ that has a higher valuation than buyer $k$. From part (i), either buyer $i$ purchases from a seller that clears at the same price as seller $j$, or it bought previously at a lower price. Therefore, buyer $i$ would not be willing to pay seller $j$ a higher price that seller $j$ receives from buyer $k$. The bidding mechanism also ensures that no buyer that does not obtain a good is linked to a seller willing to accept a price below the buyer's valuation. (The fact that the buyer is not obtaining a good implies that the prices all of its linked sellers are receiving are above the buyer's valuation.) There is also no linked seller providing a good at a lower

\footnotetext{
${ }^{49}$ The proof that $\left|L\left(\mathbf{C}^{\prime}\right)\right|=\left|\mathbf{C}^{\prime}\right|$ when $p>0$ is available from the authors on request. Intuitively, if any sellers do not sell goods, they are part of a clearable set at $p=0$.
}

price than it is paying (otherwise the set of sellers would not be clearable at that price).

\section{APPENDIX B}

\section{PROOF OF LEMMA 1:}

We show below that for any link pattern and for each realization of buyers' valuations, a buyer's payoff in the auction is equal to its contribution to the gross surplus of exchange. That is, a buyer $i$ earns the difference between $w\left(\mathbf{v}, \mathbf{A}^{*}(\mathbf{v}, \mathbf{G})\right)$ and the surplus that would arise if buyer $i$ did not purchase. Taking expectations over all the valuations, then gives us that a buyer's $V$-payoff is equal to the buyer's contribution to expected gross surplus. The difference in a buyer's $V$-payoff in any two link patterns is then the difference in the buyer's contribution to expected gross surplus in each link pattern. If two link patterns differ only in the buyer's own link holdings, the difference in the buyer's contribution to expected gross surplus in each link pattern is the same as the difference in total expected gross surplus in each link pattern. This gives the result.

Consider a realization $\mathbf{v}$ of buyers' valuations. Suppose a buyer $b_{i}$ obtains a good in the equilibrium outcome of the auction given this realization. This buyer obtains a good when there arises a maximal clearable set of sellers $\mathbf{C}$ such that $b_{i} \in$ $L(\mathbf{C})$. Suppose the price at which this clearable set arises is $p=0$. The buyer earns its valuation $v_{i}$ from the exchange, and so if this buyer did not have any links - that is, were not participating in the network -its loss in payoffs would be $v_{i}$. This loss is the same as the loss in gross surplus. By the argument in the proof of Proposition 1, in equilibrium the buyers that obtain goods from the sellers in $\mathbf{C}$ are the buyers with the highest valuations of those linked to those sellers in the original graph. When $b_{i}$ 's links are removed, the only change in this set is the removal of $b_{i}$. Thus, the loss in gross surplus is also simply $v_{i}$.

Suppose the price at which $b_{i}$ obtains a good is some $p>0$. Label the set of sellers that have already cleared $\tilde{\mathbf{C}}$, and the buyers that obtained goods from these sellers $\bar{L}(\tilde{\mathbf{C}})$. (This set of buyers need not include all the buyers linked to sellers in $\tilde{\mathbf{C}}$ in the original graph, as some buyers may have dropped out of the bidding.) By the proof of Proposition 1, these buyers are the buyers with the highest valuations of those linked to the sellers in $\tilde{\mathbf{C}}$ in the original graph. 
The remaining buyers are $\mathbf{B} \bar{L}(\tilde{\mathbf{C}})$. There is some buyer $b_{k} \in \mathbf{B} \backslash \bar{L}(\tilde{\mathbf{C}})$ with valuation $v_{k}$ $\left(v_{k}<v_{i}\right)$ that drops out the bidding and creates the maximal clearable set $\mathbf{C}$. Let $\bar{L}(\mathbf{C})$ be the set of buyers that obtain goods from the sellers in C. (These buyers are all the buyers linked to any sellers in $\mathbf{C}$ in the interim link pattern at $p$.) Note that $b_{k}$ must be linked to some seller in $\mathbf{C}$ in the original graph. Otherwise, its bid would not affect whether or not the set is clearable. Of the buyers in $\mathbf{B} \backslash \bar{L}(\tilde{\mathbf{C}})$ linked to some seller in $\mathbf{C}$ in the original graph, $b_{k}$ is the buyer with the next-highest valuation after the $|\mathbf{C}|$ buyers in $\bar{L}(\mathbf{C})$. Otherwise, $b_{k}$ would not be the buyer that caused the set to clear. A buyer with higher valuation than $b_{k}$ but not in $\bar{L}(\mathbf{C})$ still remains linked to some seller in $\mathbf{C}$, and $\mathbf{C}$ would not be clearable. In equilibrium, buyer $b_{i}$ obtains the good and pays the price $p=v_{k}$. Its surplus from the exchange is $v_{i}-v_{k}$. Now suppose that $b_{i}$ is not participating in the network. What is the loss in welfare? By the argument cited above, the buyers with the highest valuations connected to the sellers in $\mathbf{C} \cup \tilde{\mathbf{C}}$ in the original graph obtain goods from them in equilibrium. When $b_{i}$ is not participating in the network, $b_{i}$ is no longer in this set of buyers. In its place is buyer $b_{k}$. This is because we know that buyer $b_{k}$ is connected to some seller(s) in C in the original graph. And, of those buyers in $\mathbf{B} \backslash \bar{L}(\tilde{\mathbf{C}})$, the buyer $b_{k}$ has the next-highest valuation after the $|\mathbf{C}|$ buyers in $\bar{L}(\mathbf{C})$. So in the graph without $b_{i}$ 's links, the $|\mathbf{C}|$ buyers with the highest valuations of those buyers in $\mathbf{B} \backslash \bar{L}(\tilde{\mathbf{C}})$ includes $b_{k}$. Therefore, the loss in welfare is $v_{i}-v_{k}$. The same argument holds for any realization $\mathbf{v}$ in which the buyer obtains good.

\section{PROOF OF PROPOSITION 2:}

This result follows immediately from Lemma 1 . Let $\mathbf{G}^{0}=\left(\mathbf{g}_{i}^{0}, \mathbf{g}_{-i}^{0}\right)$ be an efficient graph. Formally, we can write a buyer's equilibrium conditions as follows:

$$
\begin{aligned}
\mathbf{g}_{i}^{*} & =\underset{\mathbf{g}}{\arg \max }\left\{\Pi_{i}^{b}\left(\mathbf{g}_{i}, \mathbf{g}_{-i}^{0}\right)-0\right\} \\
& =\underset{\mathbf{g}}{\arg \max }\left\{W\left(\mathbf{g}_{i}, \mathbf{g}_{-i}^{0}\right)-W\left(0, \mathbf{g}_{-i}^{0}\right)\right\} .
\end{aligned}
$$

Since the efficient graph $\mathbf{G}^{0}=\left(\mathbf{g}_{i}^{0}, \mathbf{g}_{-i}^{0}\right)$ max- imizes $W\left(\cdot, \mathbf{g}_{-i}^{0}\right)$, the solution to the buyer's maximization problem is $\mathbf{g}_{i}=\mathbf{g}_{i}^{0}$.

\section{PROOF OF PROPOSITION 3:}

By the Marriage Theorem, a network of buyers and sellers $(\mathbf{B}, \mathbf{S})$ is allocatively complete if and only if every subset of $k$ buyers in $\mathbf{B}$ is linked to at least $k$ sellers in $\mathbf{S}$ for each $k, 1 \leq$ $k \leq \bar{S}$.

First we show that $\bar{B}-\bar{S}+1$ links per seller is necessary for allocative completeness. Suppose for some seller $s_{j} \in \mathbf{S},\left|\underline{L}\left(s_{j}\right)\right|$ $\leq \bar{B}-\bar{S}$. Then there are at least $\bar{B}-(\bar{B}-$ $\bar{S})=\bar{S}$ buyers in the network that are not linked to $s_{j}$. No buyer in this set of $\bar{S}$ buyers can obtain a good from $s_{j}$. Therefore, there is not a feasible allocation in which this set of buyers obtain goods, and the network is not allocatively complete.

Second, we construct an AC network where each seller has $\bar{B}-\bar{S}+1$ links: $\bar{S}$ of the buyers have exactly one link each to a distinct seller. The remaining buyers are linked to every seller in S. It is easy to check that this network satisfies the Marriage Theorem condition above and involves $\bar{B}-\bar{S}+1$ links per seller.

\section{PROOF OF PROPOSITION 4:}

Let $\mathbf{G}$ be an LAC link pattern and let $\mathbf{G}^{\prime}$ be any other link pattern which forms an $\mathrm{AC}$ but not LAC network on (B, S). It is clear that $W(\mathbf{G})>W\left(\mathbf{G}^{\prime}\right)$, since $H(\mathbf{G})=H\left(\mathbf{G}^{\prime}\right)$, and $\mathbf{G}$ involves fewer links.

Next, let $\mathbf{G}^{\prime}$ be any graph that is not an AC network and yet yields higher welfare than $\mathbf{G}$. In $\mathbf{G}^{\prime}$ there is at least one set of $\bar{S}$ buyers that cannot all obtain goods when they have the highest $\bar{S}$ valuations. Label one such set of buyers $\tilde{\mathcal{B}}$. Below we prove that we can add exactly one link between a buyer in $\tilde{\mathcal{B}}$ and a seller not currently linked to any buyer in $\tilde{\mathcal{B}}$ so that for any realization $\mathbf{v}$ of buyers' valuations such that the buyers in $\tilde{\mathcal{B}}$ have the top $\bar{S}$ valuations, one more buyer in $\tilde{\mathcal{B}}$ obtains goods in the $\mathbf{A}^{*}\left(\mathbf{v} ; \mathbf{G}^{\prime \prime}\right)$ than in $\mathbf{A}^{*}\left(\mathbf{v} ; \mathbf{G}^{\prime}\right)$, where $\mathbf{G}^{\prime \prime}$ is the new graph formed from adding the link. Therefore, $\mathbf{A}^{*}\left(\mathbf{v} ; \mathbf{G}^{\prime \prime}\right)$ yields higher expected surplus than $\mathbf{A}^{*}\left(\mathbf{v} ; \mathbf{G}^{\prime}\right)$. What is precisely the gain in surplus? The lowest possible valuation of the buyer that obtains the good in $\mathbf{A}^{*}\left(\mathbf{v} ; \mathbf{G}^{\prime \prime}\right)$ but not in $\mathbf{A}^{*}\left(\mathbf{v} ; \mathbf{G}^{\prime}\right)$ is $X^{\bar{S}: \vec{B}}$. The highest possible valuation of the buyer outside of $\tilde{\mathcal{B}}$ that 
obtains the good in $\mathbf{A}^{*}\left(\mathbf{v} ; \mathbf{G}^{\prime}\right)$ but not in $\mathbf{A}^{*}(\mathbf{v}$; $\left.\mathbf{G}^{\prime \prime}\right)$ is $X^{\bar{S}+1: \bar{B}}$. Thus, $\mathbf{A}^{*}\left(\mathbf{v} ; \mathbf{G}^{\prime \prime}\right)$ yields an expected increase in surplus of at least $E\left[X^{\bar{S}: \bar{B}}-\right.$ $\left.X^{\bar{S}+1: \bar{B}}\right]$. Since adding a link does not decrease the surplus from the efficient allocations for other realizations of $\mathbf{v}$, and since $\left(\frac{\bar{B}}{S}\right)^{-1}$ is the probability that the set $\tilde{\mathcal{B}}$ has the top valuations, the graph $\mathbf{G}^{\prime \prime}$ yields an expected increase in gross surplus of at least $\left(\frac{\bar{B}}{S}\right)^{-1} E\left[X^{S: \bar{B}}-X^{\bar{S}+1: \bar{B}}\right]$ over $\mathbf{G}^{\prime}$. Hence, for $c<\left(\frac{\bar{B}}{S}\right)^{-1} E\left[X^{S: \bar{B}}-X^{\bar{S}+1: \bar{B}}\right], \mathbf{G}^{\prime}$ is not an efficient network. Therefore, there does not exist any graph $\mathbf{G}^{\prime}$ which yields strictly higher welfare than an LAC link pattern for $c \leq$ $\left(\frac{\bar{B}}{\bar{S}}\right)^{-1} E\left[X^{\bar{S}: \bar{B}}-X^{\bar{S}+1: \bar{B}}\right]$.

To finish the proof, we show that it is possible to add exactly one link between a buyer in $\tilde{\mathcal{B}}$ and a seller not currently linked to any buyer in $\tilde{\mathcal{B}}$ so that for any realization $\mathbf{v}$ of buyers' valuations such that the buyers in $\tilde{\mathcal{B}}$ have the top $\bar{S}$ valuations, one more buyer in $\tilde{\mathcal{B}}$ obtains goods in $\mathbf{A}^{*}\left(\mathbf{v} ; \mathbf{G}^{\prime \prime}\right)$ than in $\mathbf{A}^{*}(\mathbf{v}$; $\mathbf{G}^{\prime}$ ), where $\mathbf{G}^{\prime \prime}$ is the new graph formed from adding the link.

First we need a few definitions. We say that a set of $k$ buyers, for $k \leq \bar{S}$, is deficient if and only if it is not collectively linked to $k$ sellers. A set of $k$ buyers, for $k \leq \bar{S}$, is a minimal deficient set if and only if it is a deficient set and no proper subset is deficient. For a minimal deficient set of $k \leq \bar{S}$ buyers, the $k$ buyers are collectively linked to exactly $k-1$ sellers. (Otherwise, if they were linked to fewer buyers, the set is not a minimal deficient set.) Hence, adding one link between any buyer in the set and any seller not linked to any buyer in the set removes the deficiency.

In $\mathbf{G}^{\prime}$, by assumption, there is no feasible allocation in which the set of buyers $\tilde{\mathcal{B}}$ obtains goods. The Marriage Theorem implies that there is some subset $\tilde{\tilde{\mathcal{B}}}$ of $k$ buyers, $\tilde{\tilde{\mathcal{B}}} \subset \tilde{\mathcal{B}}$, that is not collectively linked to $k$ sellers and is thus a deficient set. Label $\mathcal{B}^{M}$ the minimal deficient set of buyers contained in $\tilde{\mathcal{B}}$. Let $N L(\tilde{\mathcal{B}})$ denote the set of sellers that are not linked to any buyer in $\tilde{\mathcal{B}}$. Add one link between any buyer in $\mathcal{B}^{M}$ and any seller in $N L(\tilde{\mathcal{B}})$. Since adding one link removes the deficiency, $\mathcal{B}^{M}$ is not deficient in $\mathbf{G}^{\prime \prime}$, the new graph formed from adding the link. Therefore, for any ordering of valuations in which the buyers in $\tilde{\mathcal{B}}$ have the top $\bar{S}$ valuations, there is a feasible allocation in which each buyer in $\mathcal{B}^{M}$ obtains a good in $\mathbf{G}^{\prime \prime}$ but not in $\mathbf{G}^{\prime}$.

\section{PROOF OF PROPOSITION 5:}

Suppose now that some link pattern $\mathbf{G}$ is an equilibrium outcome, and $\mathbf{G}$ is an $\mathrm{AC}$ but not LAC link pattern. A proof available upon request from the authors shows that all AC link patterns have subgraphs that are LAC link patterns. Since buyers earn the same $V$-payoffs in any AC (or LAC) link pattern, in $\mathbf{G}$ some buyer has a link that is redundant in the sense that the buyer can cut the link and not change its $V$ payoffs. Since $c>0$, the buyer would want to cut this link to increase its profits. Therefore, $\mathbf{G}$ cannot be an equilibrium outcome.

Suppose some link pattern $\mathbf{G}$ is an equilibrium outcome and is not $\mathrm{AC}$. Because the graph is not $\mathrm{AC}$, there is at least one minimal deficient set $\mathcal{B}^{M}$ of buyers. By Proposition 4 , there is a link that a buyer $b_{i} \in \mathcal{B}^{M}$ can add to some seller $s_{j}$, and this link increases gross surplus by $\left(\frac{\bar{B}}{S}\right)^{-1} E\left[X^{\bar{S}: \bar{B}}-X^{\bar{S}+1: \bar{B}}\right]$. By Lemma 1, buyer $i$ earns this increase in surplus in its $V$-payoffs. Hence, $b_{i}$ has an incentive to add the link for $c<\left(\frac{\vec{B}}{S}\right)^{-1} E\left[X^{\bar{S}: \bar{B}}-X^{\bar{S}+1: \bar{B}}\right]$. This contradicts the assumption that $\mathbf{G}$ is an equilibrium for this range of link costs.

We have shown that the only equilibrium outcomes that are possible for the hypothesized range of link costs are LAC networks. By Proposition 2, the efficient link pattern is always an equilibrium outcome, and by Proposition 4, LAC's are the efficient patterns for this range of costs. Hence, in this range of costs, only efficient networks (i.e., LAC's) are equilibrium outcomes of the game.

\section{REFERENCES}

Bala, Venkatesh and Goyal, Sanjeev. "A NonCooperative Model of Network Formation." Econometrica, September 2000, 68(5), pp. 1181-229.

Bose, R. C. and Manvel, B. Introduction to combinatorial theory. New York: Wiley, 1984.

Carlton, Dennis W. "Market Behavior with Demand Uncertainty and Price Inflexibility." American Economic Review, September 1978, 68(4), pp. 571-87.

Casella, Alessandra and Rauch, James E. "Anonymous Market and Group Ties in International Trade." Centre for Economic Policy Research Discussion Paper No. 1748, November 1997. 
Cawthorne, Pamela M. "Of Networks and Markets: The Rise and Rise of a South Indian Town, the Example of Tiruppur's Cotton Knitwear Industry." World Development, January 1995, 23(1), pp. 43-56.

Coase, R. H. "The Nature of the Firm." Economica, November 1937, 4(15), pp. 386405.

Demange, Gabrielle; Gale, David and Sotomayor, Marilda. "Multi-Item Auctions." Journal of Political Economy, August 1986, 94(4), pp. 863-72.

Demski, Joel S.; Sappington, David E. M. and Spiller, Pablo T. "Managing Supplier Switching." Rand Journal of Economics, Spring 1987, 18(1), pp. 77-97.

de Soto, Hernando. The other path. New York: Harper \& Row, 1989.

Dutta, Bhaskar; van-den-Nouweland, Anne and Tijs, Stef. "Link Formation in Cooperative Situations." International Journal of Game Theory, July 1998, 27(2), pp. 245-56.

Farrell, Joseph and Gallini, Nancy T. "SecondSourcing as a Commitment: Monopoly Incentives to Attract Competition." Quarterly Journal of Economics, November 1988, 103(4), pp. 673-94.

Farrell, Joseph and Rabin, Matthew. "Cheap Talk." Journal of Economic Perspectives, Summer 1996, I0(3), pp. 103-18.

Feller, William. An introduction to probability theory and its applications. New York: Wiley, 1950.

Greif, Avner. "Contract Enforceability and Economic Institutions in Early Trade: The Maghribi Traders' Coalition." American Economic Review, June 1993, 83(3), pp. 525-48.

Grossman, Sanford J. and Hart, Oliver D. "The Costs and Benefits of Ownership: A Theory of Vertical and Lateral Integration." Journal of Political Economy, August 1986, 94(4), pp. 691-719.

Gul, Faruk and Stacchetti, Ennio. "The English Auction with Differentiated Commodities." Journal of Economic Theory, May 2000, 92(1), pp. 66-95.

Hart, Oliver and Moore, John. "Property Rights and the Nature of the Firm." Journal of Political Economy, December 1990, 98(6), pp. 1119-58.

Helper, Susan and Levine, David I. "Long-Term Supplier Relations and Product-Market
Structure." Journal of Law, Economics, and Organization, October 1992, 8(3), pp. 56181.

Hendricks, Ken; Piccione, Michele and Tan, Guofo. "Equilibria in Networks." Econometrica, November 1999, 67(6), pp. 1407-34.

Humphrey, John. "Industrial Organization and Manufacturing Competitiveness in Developing Countries: Introduction." World Development, January 1995, 23(1), pp. 1-7.

Jackson, Matthew O. and Watts, Alison. "The Evolution of Social and Economic Networks." Mimeo, California Institute of Technology and Vanderbilt University, 1998.

Jackson, Matthew O. and Wolinsky, Asher. "A Strategic Model of Social and Economic Networks." Journal of Economic Theory, October 1996, 71(1), pp. 44-74.

Katz, Michael L. and Shapiro, Carl. "Systems Competition and Network Effects." Journal of Economic Perspectives, Spring 1994, 8(2), pp. 93-115.

Kranton, Rachel E. "Reciprocal Exchange: A Self-Sustaining System." American Economic Review, September 1996, 86(4), pp. $830-51$.

Kranton, Rachel E. and Minehart, Deborah F. "Link Patterns in Buyer-Seller Networks: Incentives and Efficiency in Graphs." Mimeo, University of Maryland and Boston University, 1997.

"Competition for Goods in BuyerSeller Networks." Review of Economic Design, September 2000a, 5(3), pp. 301-31.

"Networks versus Vertical Integration." Rand Journal of Economics, Autumn 2000b, 31(3), pp. 570-601.

Landa, Janet Tai. Trust, ethnicity, and identity: Beyond the new institutional economics of ethnic trading networks, contract law, and gift-exchange. Ann Arbor, MI: University of Michigan Press, 1994.

Lazerson, Mark. "Factory or Putting-Out? Knitting Networks in Modena," in Gernot Grabher, ed., The embedded firm: On the socioeconomics of industrial networks. New York: Routledge, 1993, pp. 203-26.

Leonard, Herman B. "Elicitation of Honest Preferences for the Assignment of Individuals to Positions." Journal of Political Economy, June 1983, 91(3), pp. 461-79.

Lorenz, Edward H. "The Search for Flexibility: 
Subcontracting Networks in British and French Engineering," in Paul Hirst and Jonathan Zeitlin, eds., Reversing industrial decline? Industrial structure and policy in Britain and her competitors. New York: St. Martin's Press, 1989, pp. 122-32.

Macauley, Stewart. "Noncontractual Relations in Business: A Preliminary Study." American Sociological Review, February 1963, 28(1), pp. 55-70.

McMillan, John and Woodruff, Christopher. "Interfirm Relationships and Informal Credit in Vietnam." Quarterly Journal of Economics, November 1999, 114(4), pp. 1285-320.

Myerson, Roger B. "Graphs and Cooperation in Games." Mathematics of Operations Research, 1977, 2(3), pp. 225-29. . "Optimal Auction Design." Mathematics of Operations Research, 1981, 6(1), pp. 58-73.

Myerson, Roger B. and Satterthwaite, Mark A. "Efficient Mechanisms for Bilateral Trading." Journal of Economic Theory, April 1983, 29(2), pp. 265-81.

Nishiguchi, Toshihiro. Strategic industrial sourcing. New York: Oxford University Press, 1994.

Piore, Michael J. and Sabel, Charles F. The second industrial divide. New York: Basic Books, 1984.

Rabellotti, Roberta. "Is There an 'Industrial District Model'? Footwear Districts in Italy and Mexico Compared." World Development, January 1995, 23(1), pp. 29-41.

Riordan, Michael H. "Contracting with Qualified Suppliers." International Economic Review, February 1996, 37(1), pp. 115-28.
Roth, Alvin E. and Sotomayor, Marilda A. OIiveira. Two-sided matching: A study in gametheoretic modeling and analysis. New York: Cambridge University Press, 1990.

Rothschild, Michael and Werden, Gregory J. "Returns to Scale from Random Factor Services: Existence and Scope." Bell Journal of Economics, Spring 1979, 10(1), pp. 329-35.

Saxenian, Annalee. Regional advantage: Culture and competition in Silicon Valley and Route 128. Cambridge, MA: Harvard University Press, 1994.

Scheffman, David T. and Spiller, Pablo T. "Buyer's Strategies, Entry Barriers, and Competition." Economic Inquiry, July 1992, 30(3), pp. 418-36.

Schmitz, Hubert. "Small Shoemakers and Fordist Giants: Tale of a Supercluster." World Development, January 1995, 23(1), pp. 9-28.

Scott, Allen J. Technopolis. Berkeley, CA: University of California Press, 1993.

Shapley, Lloyd S. and Shubik, Martin. "The Assignment Game I: The Core." International Journal of Game Theory, 1972, 1, pp. 11130.

Spulber, Daniel F. "Market Microstructure and Intermediation." Journal of Economic Perspectives, Summer 1996, 10(3), pp. 13552.

Uzzi, Brian. "The Sources and Consequences of Embeddness for the Economic Performance of Organizations: The Network Effect." American Sociological Review, August 1996, 61(4), pp. 674-98.

Williamson, Oliver E. Markets and hierarchies: Analysis and antitrust implications. New York: Free Press, 1975. 